\title{
Development of Gluten-Free Egg Pasta based on Amaranth, Maize and Sorghum
}

\author{
Laura Paux ${ }^{1} \&$ Kurt A. Rosentrater ${ }^{1}$ \\ ${ }^{1}$ Iowa State University, USA \\ Correspondence: Kurt Rosentrater, Iowa State University, USA. E-mail: karosent@ iastate.edu
}

Received: August 18, 2018

Accepted: September 7, $2018 \quad$ Online Published: September 22, 2018

doi:10.5539/jfr.v7n6p16

URL: https://doi.org/10.5539/jfr.v7n6p16

\begin{abstract}
Due to increase of the population affected by Coeliac disease and awareness of consumers about the relationship between food and health, the production of cereal products from raw materials other than wheat is of interest. The aim of the work was to produce good quality gluten-free spaghettis, based on sorghum, amaranth and maize flour. Response surface methodology was applied to determine optimal formulation for the production of pasta. The resulting products of the experimental design were characterized regarding humidity, color, density, water activity, texture (firmness and elasticity), optimal cooking time, cooking weight, and cooking loss. The main trials were compared to two industrials gluten-free spaghetti. The results showed that water activity and cooking weight of the main trials were similar to the industrials pasta, but were really different for the other studied parameters. The optimal formulation was determined in order to obtain pasta with low cooking loss and optimal color and texture firmness. It utilized $12 \%$ egg white, $60 \%$ maize flour, $30 \%$ sorghum flour, $10 \%$ amaranth flour, $2.4 \%$ guar gum and $36 \%$ water. The optimal formulated pasta was evaluated by an untrained consumer panel in a sensorial analysis to show the consumer acceptance. The product presents nutritional benefits, the color was appreciated, but the texture was granular and crumbly which was not liked by the consumers.
\end{abstract}

Keywords: gluten-free pasta, amaranth, sorghum, maize, cooking loss, texture, color

\section{Introduction}

Pasta is a traditional Italian cereal-based food that is popular worldwide because of its convenience, versatility, sensory and nutritional value. The term usually refers to unleavened extruded wheat dough, composed simply of flour and water, sometimes egg (Fuad \& Prabhasankar, 2010). Yet, the problem with wheat pasta is that the gliadins and glutenins of wheat gluten contain protein sequences toxic to persons with celiac disease (Verdu et al., 2015).

Coeliac disease is a chronic immune-mediated enteropathy triggered by the ingestion of gluten in wheat, rye and barley, in patients who are HLA-DQ2 or HLA-DQ8 positive (Verdu et al., 2015). It is characterized by a strong immune response to certain amino acid sequences found in the prolamin fractions of gluten, resulting in the destruction of the villi in the small intestine and leading to the malabsorption of nutrients, thus adversely affecting all systems of the body (Ciacci et al., 2007). Currently, the only effective treatment for CD is the strict lifelong renunciation of gluten-containing foods (Feighery, 1999). In the United States, about one percent of the population is affected by the Coeliac disease and one person in one hundred people suffer from celiac disease worldwide. Such a rate establishes that CD is the most common food intolerances (Broz \& Horne, 2007). And it appears that this disease, and other gluten intolerances are increasing worldwide.

Durum wheat proteins are characterized by a typical viscoelastic behavior, provided by the protein-starch interaction, that allows good networking of the matrix and optimal dough formation during the mixing and extrusion phases. Therefore, the network forming ability of gluten, preventing the dissolution of pasta during cooking, needs to be substituted by other means, in order to achieve products with satisfying quality (Feillet \& Dexter, 1996).

The use of gluten-free cereals like maize, millet, sorghum, or even non-grass pseudocereals like amaranth, quinoa, or buckwheat, can be a big challenge for food research and development as well as commercial processing operations. The advantage of using such raw material is that it could improve the nutritional quality of gluten-free foods (Schoenlechner et al., 2010). 
However, several studies show that the production of pasta based solely on gluten-free flours is unsuccessful, and additional structuring agents are necessary to obtain extrudable dough. An obvious ingredient to increase the protein content is egg. Eggs are traditionally used in pasta mainly to achieve flavour effects and also to aid the structure formation. Egg proteins facilitate the formation of a tighter protein network, yielding a harder product, both before and after cooking. In addition, the tighter protein network reduces penetration by water and hence starch granule swelling during cooking (Antognelli, 1980).

Amaranth, an ancient grain, contains about thirty percent more protein than cereals such as rice, sorghum and rye. Amaranth is a source of thiamine, niacin, riboflavin, folate, and dietary minerals including calcium, iron, magnesium, phosphorus, zinc, and manganese that are comparable to grain products such as wheat germ, oats, and others. Amaranth flour particularly has an unusually rich source of the essential amino acid, lysine, which is low in other grains (George et al., 2015).

Sorghum is a cereal grain, rich in glucides ( $70 \%$ of starch), it contains about $12 \%$ of proteins, mostly polyunsaturated fatty acids, fibres, minerals and vitamins (B1, B2, B3). The flour produced from sorghum is light in color and has a bland, neutral taste that does not impart unusual colors or flavors to food products. These attributes make it desirable for use in wheat-free food products. However this grain contains also anti-nutrients such as tannins, which reduce the digestibility of the product (FAO, 1995).

Like sorghum, maize is mostly constituted of starch ( 72\%). This grain contains also proteins $(\sim 10 \%)$, essential fatty acids (such as linolenic acid), fibers and vitamins (A and E) (FAO, 1992). This combination of these three grains in the gluten free pasta formulation could add value to the final product and limit the negatives aspects of each grain individually.

To the authors' knowledge, no publications exist on the production of pasta from a combination of amaranth, maize and sorghum. The aim of this study was to develop amaranth, maize and sorghum pasta of similar quality to wheat pasta. A response surface methodology was applied to determine the optimal formulation in a minimal number of experimental trials. The gluten free pastas produced during this study were characterized regarding various physical properties, functional properties, and sensorial analysis.

\section{Material and Methods}

\subsection{Raw Materials}

The amaranth used in the experiment was organic whole grain amaranth of variety Amaranthus Hypochiondriacus (11.7\% moisture) and was donated to Iowa State University by Mark \& Marice Jones (4498 Rd. 167 Oshkosh, NE 69154, United States). The sorghum (6.47\% moisture) was supplied by Woodland Ingredients (Waukegan, IL 60087, United States) and the Maize flour (4.34\% moisture) by Premium White Corn (Honeyville, Utah, 84314, United States). The brand of the emulsifier, guar gum, added to the pasta formulation was Bob's Red Mill and was bought in Hyvee (Ames, IA, United States). The eggs were grade A large eggs and were purchased in Hyvee (Ames, IA, United States).

\subsection{Pasta Manufacture}

A small-scale standardized laboratory procedure was used for pasta manufacture. The sorghum and amaranth grains were firstly milled into flour in Magic Bullet blender (Model MB1001). Then all dried components of the formula (maize flour, sorghum flour, amaranth flour, and guar gum) were mixed in a Kitchen Aid mixer (Model KSM75WH) at low speed until a uniform mix was achieved. Whole liquid eggs and water were added and mixed at low speed until the "dough" had an adequate consistency for lamination. The dough was at the end kneaded by hand and put into the Stand-Mixer Pasta Extruder Attachment of the Kitchen Aid. The pasta were arranged on trays and dried at room temperature for 24 hours. They were then packed in plastic bags (Ziploc) to protect them from the humidity.

\subsection{Experimental Design}

Preliminary trials (Table 1) were conducted to study the flour behaviors, the impact of whole or egg whites, and the average level of water needed for the pasta manufacture. All formulations were manufactured in duplicate. 
Table 1. Formulations of the Pre-Trials

\begin{tabular}{lllllllllll}
\hline & \multicolumn{10}{c}{ Trials } \\
\cline { 2 - 11 } Ingredients & 1 & 2 & 3 & 4 & 5 & 6 & 7 & 8 & 9 & 10 \\
Sorghum flour (\%) & 30 & 50 & 40 & 10 & 20 & 40 & 20 & 20 & 25 & 20 \\
Amaranth flour (\%) & 20 & 20 & 30 & 20 & 10 & 10 & 30 & 30 & 25 & 40 \\
Maize flour (\%) & 50 & 30 & 30 & 70 & 70 & 50 & 50 & 50 & 50 & 40 \\
Egg white (\%) & 12 & 13 & - & 12 & - & - & 12 & - & 12 & 13 \\
Whole egg (\%) & - & - & 20 & - & 12 & - & - & 12 & - & - \\
Water (\%) & 40 & 35 & 30 & 45 & 40 & 37 & 35 & 35 & 32 & 33 \\
Emulsifier (\%) & 1.2 & 1.2 & 1.2 & 1.2 & 1.2 & 1.2 & 1.2 & 1.2 & 1.2 & 1.2 \\
\hline
\end{tabular}

Some difficulties occurred during the extrusion of pasta containing more than $30 \%$ of sorghum flour. The best and easiest extrudable pasta were those with a large percentage of maize flour.

According to the comparison between the pre trials 7 and 8 it was noticeable that the pasta with egg white were of better quality than pasta with whole egg. Consequently, the main trials were manufactured using only egg white.

Dough moisture is generally recognized to have a major influence on pasta quality. High dough moisture toughened the dough, which adhered to the screw of the pasta machine and the produced pasta were very sticky and therefore showed very low texture firmness. Too low dough moisture resulted in noodles, which showed surface cracks. After these pre trials it was decided to work with dough moisture levels between 33 and 39\%.

Response surface methodology was then used to evaluate the effect of the independent variables (egg white amount, amaranth and sorghum ratio, level of water, and emulsifier) on the dependent variables (firmness, color, density and cooking loss). Hereupon, optimum ingredient levels could be determined. A Doehlert design (Table 2) was developed featuring variations in the addition of egg white (ranging from 0 to $24 \%$ based on $100 \%$ maize sorghum and amaranth flour), sorghum and amaranth flour (ranging from 5\% sorghum $/ 35 \%$ amaranth to $35 \%$ sorghum/ 5\% amaranth, using a constant level in each sample of 60\% of maize flour), levels of water (ranging from 33 to $39 \%$ based on $100 \%$ maize sorghum and amaranth flour), and emulsifier (ranging from 0 to $2,4 \%$ based on $100 \%$ flour). The upper and lower limits of these levels were selected based on preliminary trials conducted. A total of 21 trials were carried out, with duplicates formulated for each treatment. The response of each of the investigated parameters was analyzed by fitting quadratic models to the data with least square regression in order to identify significant $(\mathrm{p}<0.05)$ effects of the variations in ingredient levels on the responses. Nine-dimensional graphs for the models were used to visualize overall trends. Commercial pastas (Barilla and Royal Quinoa) were also analyzed and served as the baseline comparisons. 
Table 2. Formulations of the Main Pasta Trials

\begin{tabular}{ccccc}
\hline Trial/Sample & \% Egg White & \% Sorghum /Amaranth & \% Water & \% Guar Gum \\
\hline 1 & 12 & $20 / 20$ & 36 & 1.2 \\
\hline 2 & 24 & $20 / 20$ & 36 & 1.2 \\
\hline 3 & 18 & $35 / 5$ & 36 & 1.2 \\
\hline 4 & 18 & $25 / 15$ & 39 & 1.2 \\
\hline 5 & 18 & $25 / 15$ & 37 & 2.4 \\
\hline 6 & 0 & $20 / 20$ & 36 & 1.2 \\
\hline 7 & 6 & $5 / 35$ & 36 & 1.2 \\
\hline 8 & 6 & $15 / 25$ & 33 & 1.2 \\
\hline 9 & 6 & $15 / 25$ & 35 & 0 \\
\hline 10 & 18 & $5 / 35$ & 36 & 1.2 \\
\hline 11 & 18 & $15 / 25$ & 33 & 1.2 \\
\hline 12 & 18 & $15 / 25$ & 35 & 0 \\
\hline 13 & 6 & $35 / 5$ & 36 & 1.2 \\
\hline 14 & 12 & $30 / 10$ & 33 & 1.2 \\
\hline 15 & 12 & $30 / 10$ & 35 & 0 \\
\hline 16 & 6 & $25 / 15$ & 39 & 1.2 \\
\hline 17 & 12 & $10 / 30$ & 39 & 1.2 \\
\hline 18 & 12 & $20 / 20$ & 38 & 0 \\
\hline 19 & 6 & $25 / 15$ & 37 & 2.4 \\
\hline 20 & 12 & $10 / 30$ & 37 & 2.4 \\
\hline 21 & 12 & $20 / 20$ & 34 & 2.4 \\
\hline
\end{tabular}

\subsection{Determination of Physical Properties}

Each of the following properties were measured in duplicate or triplicate, and were carried out using approved and published methods. All properties were compared to control samples, which included commercial Barilla and Royal Quinoa Pasta.

\section{Moisture content}

The moisture content of flours and pasta were determined according to the AACC (American Association of Cereal Chemists) 44-19. Two grams of flour or dry pasta were placed into a laboratory oven (Heratherm General Protocol Ovens, ThermoFisher Scientific, Waltham, Massachusetts, United States) at $135^{\circ} \mathrm{C}$ for two hours. The samples were then weighed and the percentage of moisture and volatile matter (MVM) were calculated using the following equation:

$$
\mathrm{MVM}=\frac{\text { loss of moisture }(\mathrm{g})}{\text { initial weigh of the sample }(\mathrm{g})} * 100
$$

\section{Color analysis}

A Chroma meter (CR-400, Konica Minolta, Ramsey, New Jersey, United States) was used to study the color of the pasta, according to the Reflectance Colorimeter Method 14-22 of AACC. The L* value quantify the brightness, $a^{*}$ the redness and $b^{*}$ the yellowness. $\Delta E$ value is dependent of $L^{*}, a^{*}$ and $b^{*}$ and is used to determine if there is a significant color difference between the samples.

\section{Unit density}

According to Rosentrater et al. (2005), the density of the pasta was calculated using the following equation:

$$
\text { density }\left(\mathrm{g} / \mathrm{cm}^{3}\right)=\frac{\text { Weight of the pasta }(\mathrm{g})}{\text { Volume of the pasta }\left(\mathrm{cm}^{3}\right)}
$$

The volume was calculated, assuming the pasta to be a cylinder: $V=\pi^{*} r^{2 *} 1$. The diameter $(d=r / 2)$ and the length (l) were measured using an electronic digital caliper (Digital Caliper, Fisher Scientific, Pittsburgh, Pennsylvania, United States).

\section{Water Activity}

The water activity was measured for each sample of the main trials pasta with a water activity meter (3TE, Aqua Lab, Washington, United States). 


\section{Texture}

Dried pasta texture measurements were carried out with an Autograph (Model AGS-J, Shimadzu Scientific Instruments, 8052 Reeder Street, Lenexa, KS, United States). Data were evaluated using the Trapezium Software. Tests were carried out at $20^{\circ} \mathrm{C}$ on all the 21 samples, in triplicate, and on the two reference pasta. The autograph evaluated the maximum stress $\left(\mathrm{N} / \mathrm{m}^{2}\right)$, maximum strain $(\%)$, the force $(\mathrm{N})$ applied and the stroke $(\mathrm{mm})$. The speed was adjusted to $1 \mathrm{~mm} / \mathrm{min}$.

With the raw data (stroke and force), the stress and the strain were calculated and the graph stress dependent of the strain were plot.

$$
\sigma=\frac{\mathrm{F}^{*} \mathrm{~L}}{\pi^{*} \mathrm{r}^{\wedge} 3} \quad \varepsilon=\frac{6^{*} \mathrm{D}^{*} \mathrm{~d}}{\mathrm{~L}^{2}}
$$

Where $\sigma$ is the stress $\left(\mathrm{N} / \mathrm{m}^{2}\right), \mathrm{L}(\mathrm{mm})$ is the length of the area where the pasta is placed on the fixture, $\mathrm{r}(\mathrm{mm})$ is the radius of the pasta, $\varepsilon(\%)$ is the strain, $\mathrm{D}(\mathrm{mm})$ is the stroke of the fixture, and $\mathrm{d}(\mathrm{mm})$ the diameter of the pasta. Strain is "deformation of a solid due to stress", and stress is force per unit area. The toughness and the Young's Modulus were then determined with the graph Stress $=f($ Strain $)$. The toughness is the area under the curve and these values were calculated using the trapezium method (Fuad \& Prabhasankar, 2010), and the Young Modulus corresponds to the slope of the breaking straight line.

\subsection{Determination of Functional Properties}

Cooking quality of the manufactured pasta was evaluated using official methods 66-50 and 66-51 of the American Association of Cereal Chemists (AACC, 2000). Optimum cooking time, weight gain by pasta, and solid lost during cooking were evaluated.

\section{Cooking Time}

Optimum cooking time for pasta was the time required for the opaque central core of the noodle to disappear when squeezed gently between two glass plates (Approved Method 66-50, AACC, 2000). In a 500 ml beaker about $300 \mathrm{ml}$ of water were heated until boiling. Ten $\mathrm{g}$ noodles were put into the boiling water (no salt addition) without stopping the water from boiling. Every $30 \mathrm{~s}$, one noodle was taken out and pressed between two glass plates. At the time when a white core could no longer be seen the cooking time was reached. This time was noted as the cooking time and used for the following evaluations. As the cooking time depends very much on the noodle formulation and processing conditions, it had to be determined for each formulation.

\section{Cooking Weight}

Cooking weight is defined as the weight gain of the noodles during cooking and indicates the amount of water that is absorbed and is therefore an index for the swelling ability of the noodles. According to the AACC Approved Method 66-50, $10 \mathrm{~g}$ dry spaghetti sample were cooked at the optimum cooking time and were drained and then weighted. The cooking weight was calculated and given in $\%$ using the following equation:

$$
\% \text { cooking weight }=\frac{\text { MCS-MRS }}{\text { MRS }} * 100
$$

Where MCS is the mass of cooked sample (g) and MRS is the mass of raw sample $(\mathrm{g})$.

\section{Cooking Loss}

Dry matter losses during cooking were determined by AACC Approved Method 66-50. Pasta samples (10 g) were cooked to optimum time in $300 \mathrm{~mL}$ of distilled water in a beaker, rinsed in a stream of cold water for $30 \mathrm{~s}$ and drained. Instead of collecting cooking and rinse water in the Approved Method, the pasta were dried in the oven at $50^{\circ} \mathrm{C}$ during 48 hours and then weighted. The percentage of cooking loss was calculate with following equation:

$$
\% \text { cooking loss }=\frac{\text { mass of the cooking loss }(\mathrm{g})}{\text { mass of raw pasta sample }(\mathrm{g})} * 100
$$

Where the mass of cooking loss is the difference of weight between the raw pasta sample and the pasta after cooking and drying.

\subsection{Sensory Evaluation}

Pasta made with the optimal formulation were evaluated by a consumer panel. They were made one week before the sensory analysis and kept in plastic bags at refrigeration temperatures $\left(4-6{ }^{\circ} \mathrm{C}\right)$ until the date of the analysis. They were compared to Barilla and Royal Quinoa Pasta. Pasta samples were cooked at the optimal cooking time strained, rinsed, and cooled in water at $20^{\circ} \mathrm{C}$. Before testing pasta were placed in plastic cups for evaluation. 
Samples were evaluated for the degree of liking for the color, odor, taste, texture (mouth), and overall liking. Participants were instructed to rinse with water $\left(20^{\circ} \mathrm{C}\right)$ before they began testing and between samples. Participants were briefed on the objective of the study without revealing any information that might have compromised the validity of the test. Ten healthy adults participated in the study. All participants had consumed pasta before. Rating were collected using a 5-hedonic scale where $1=$ "dislike extremely" and $5=$ "like extremely". The mid-point of the scale $3=$ neither like nor dislike. Participants were asked to complete paper ballots. They were also asked which pasta they preferred between the three without sauce and with tomato sauce, to see if they will be able to appreciate the pasta with sauce.

\section{Results and Discussion}

To evaluate the results of each analysis, the samples were compared to two industrial pastas: Barilla spaghetti, made with rice and maize flour, and Royal Quinoa spaghetti, made with quinoa flour.

\subsection{Physical Properties}

\section{Pasta moisture}

The pasta moisture is the amount of water content in the pasta. It was measured using the 44-19 AACC method. Results are shown in Figure 1.

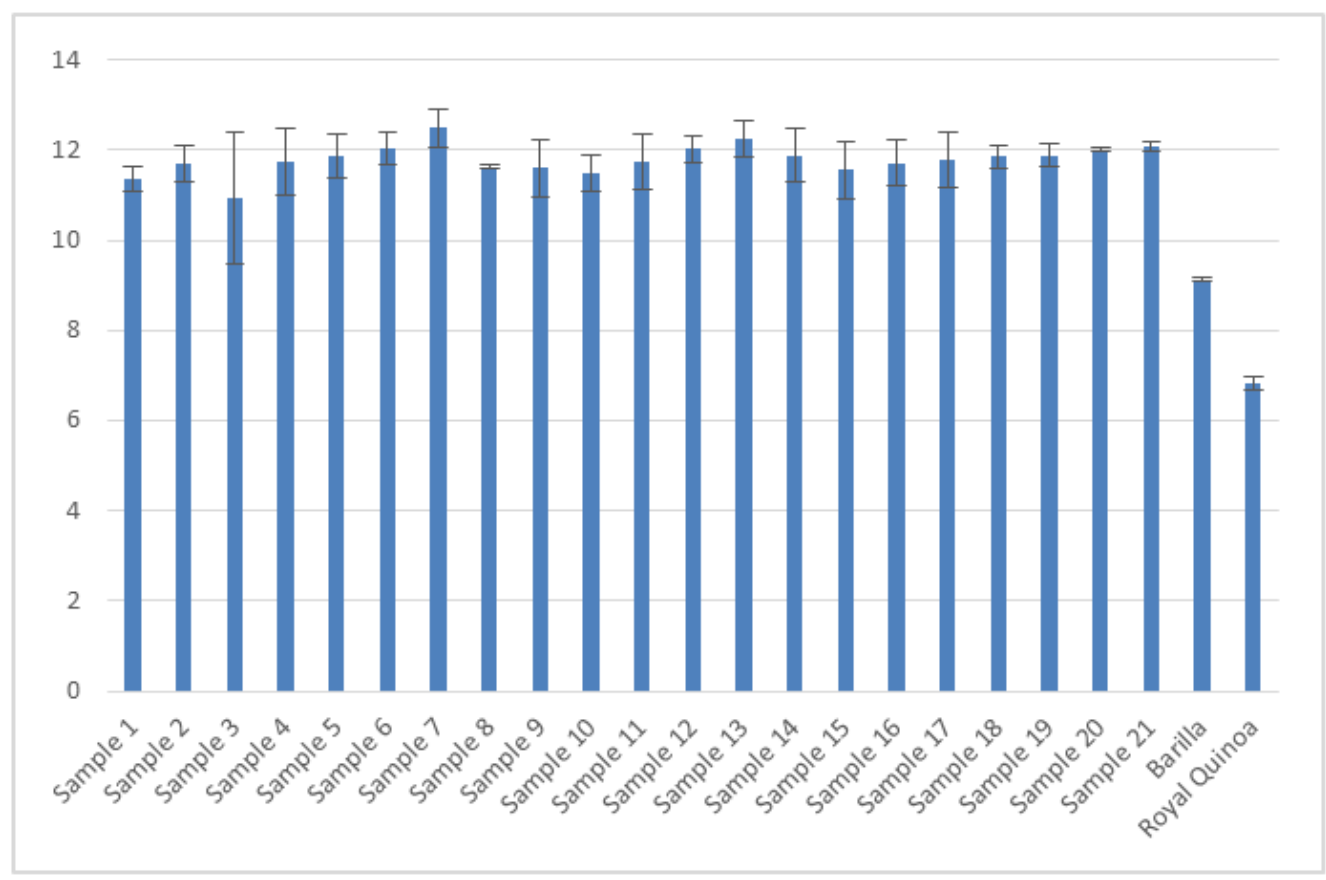

Figure 1. Moisture Content of the Trial Pastas and the Reference Pastas (+/- 1 SD)

The moisture content in Barilla and Royal Quinoa pasta were lower than in the 21 sample. The main trials were dried at room temperature for 24 hours, but the drying technology of industrial pasta is certainly different, explaining the difference between them. It is well known today that the high temperature drying technologies have a positive effect on the pasta quality (Novaro et al, 1993). Indeed, a high temperature drying could improve the firmness of the spaghetti and reduce the cooking loss (Dexter et al, 1983).

\section{Pasta color}

Color of dry spaghetti is an important quality factor for U.S. consumers. It is one of the first criterion selection, which will incite the consumer to buy, or not the product. Multigrain breads are darker and coarser than white breads, yet the market for these bread loaves has grown and expanded. Multigrain pastas may have the advantage of being perceived by a section of the population as a pasta variety related to wellness (Rayas-Duarte et al., 1996). 


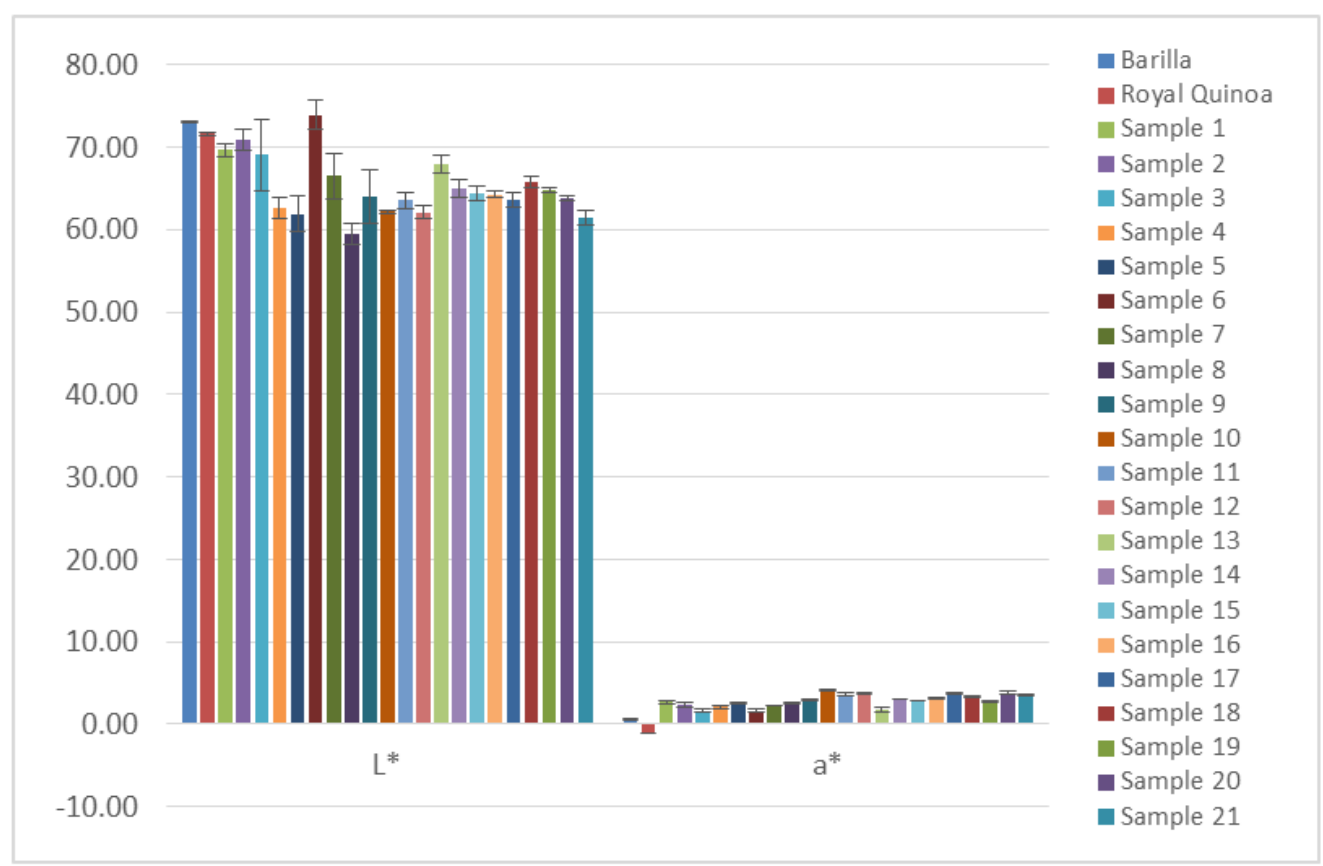

Figure 2. $\mathrm{L}^{*}$ and $\mathrm{a}^{*}$ Values of the Trial Pastas and the Reference Pastas (+/- $\left.1 \mathrm{SD}\right)$

The $L^{*}$ value (Figure 2), brightness, of the references was similar to the $L^{*}$ value of the samples $1,2,3,6$ and 13 and in the same order of value of the other samples. The $a^{*}$ value (Figure 2), redness, was much lower for the references compared to the trials.

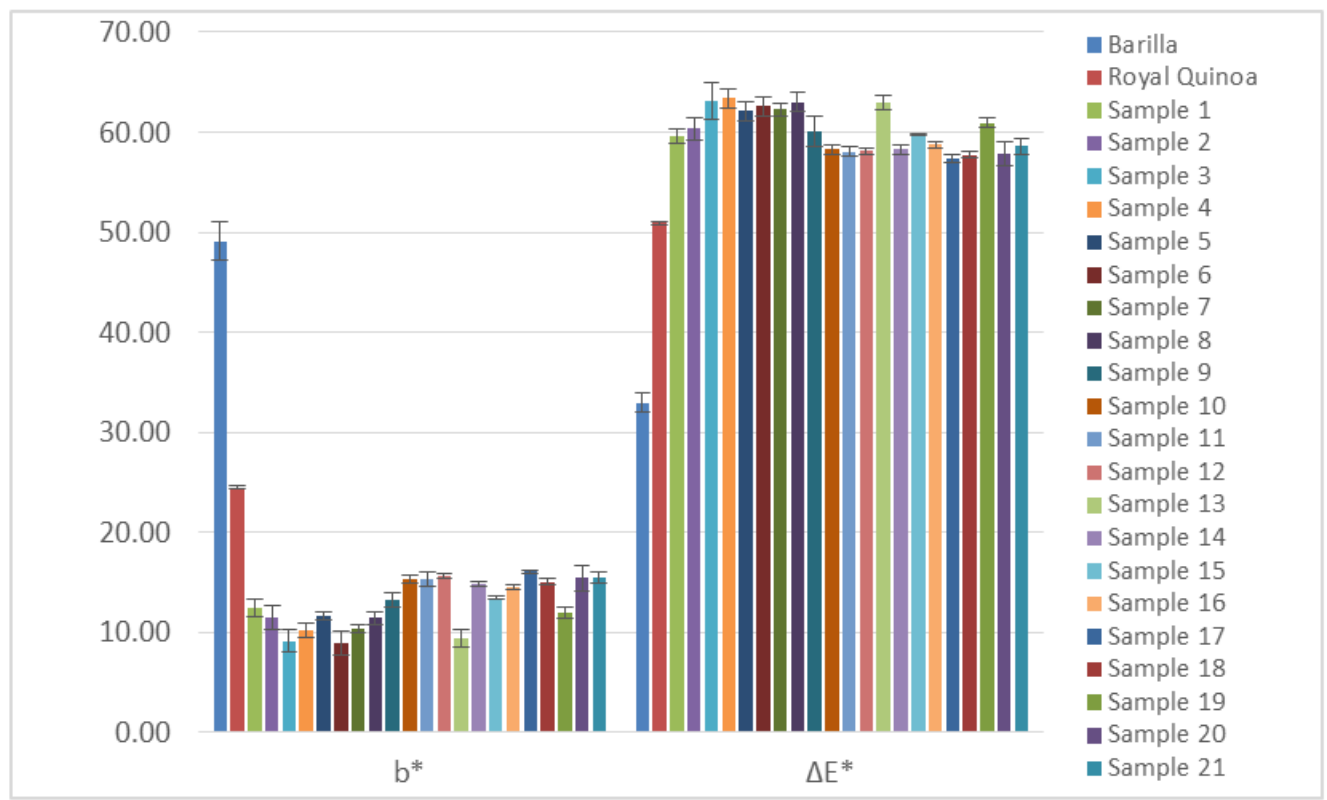

Figure 3. $b^{*}$ and $\Delta \mathrm{E}^{*}$ Value of the Trial Pastas and the Reference Pastas (+/- $\left.1 \mathrm{SD}\right)$

The $b^{*}$ value (Figure3), greenness, of the references was really different from the trial values. These results are explained by the fact that Barilla pasta were much more yellow than the Royal Quinoa Pasta and the trials. This difference of $b^{*}$ explains the difference of color between the samples and the references.

The $\Delta E$ value (Figure 3 ) was calculated using $L^{*}, a^{*}$ and $b^{*}$ values. Studying the previous graph, there was no significant difference between all the trials: they had almost the same color. However comparing the Barilla pasta to the trials, there was a major color difference, but this difference as less important between the Royal Quinoa pasta and the trials. A photo of the main trials pasta and the industrials pasta is presented in Figure 7. 
The analysis of variance for color properties of pastas is presented in Table 3. The predictive models developed for color $\left(\mathrm{L}^{*}, \mathrm{a}^{*}\right.$ and $\mathrm{b}^{*}$ ) were considered adequate because they possessed a non-significant lack of fit and had satisfactory levels of $\mathrm{R}^{2}$, and model significance.

Table 3. Analysis of Variance for Color Properties of the Pastas

\begin{tabular}{|c|c|c|c|c|c|}
\hline Response & Source & Df & Sum of squares & F value & p value \\
\hline \multirow[t]{2}{*}{ Color L* } & Model & 4 & 33.044 & 3.4493 & 0.01281 \\
\hline & Residual & 6 & 14.370 & & \\
\hline \multirow[t]{2}{*}{$R^{2}=0.805$} & Lack of fit & 6 & 14.370 & & \\
\hline & Pure error & 0 & 0.0000 & & \\
\hline \multirow[t]{2}{*}{ Color a* } & Model & 4 & 4.4006 & 14.2159 & 0.00507 \\
\hline & Residual & 6 & 0.4643 & & \\
\hline \multirow[t]{2}{*}{$R^{2}=0.861$} & Lack of fit & 6 & 0.4643 & & \\
\hline & Pure error & 0 & 0.0000 & & \\
\hline \multirow[t]{2}{*}{ Color b* } & Model & 4 & 28.318 & 9.1665 & 0.00442 \\
\hline & Residual & 6 & 4.634 & & \\
\hline \multirow[t]{2}{*}{$R^{2}=0.867$} & Lack of fit & 6 & 4.634 & & \\
\hline & Pure error & 0 & 0.0000 & & \\
\hline
\end{tabular}

The significant variables affecting the $\mathrm{L}^{*}$ parameter wereX2 (ratio sorghum/amaranth), and the interaction $\mathrm{X} 2$ :X3 (with X3 the amount of water). $\mathrm{a}^{*}$ and $\mathrm{b}^{*}$ parameters were affected by the amount of egg whites (X1), the sorghum/amaranth ratio (X2) and the interaction (X1:X2) between these two factors. Surface plots were generated for the $b^{*}$ response to describe the quality response of these parameters (Figures 4,5 and 6 ).
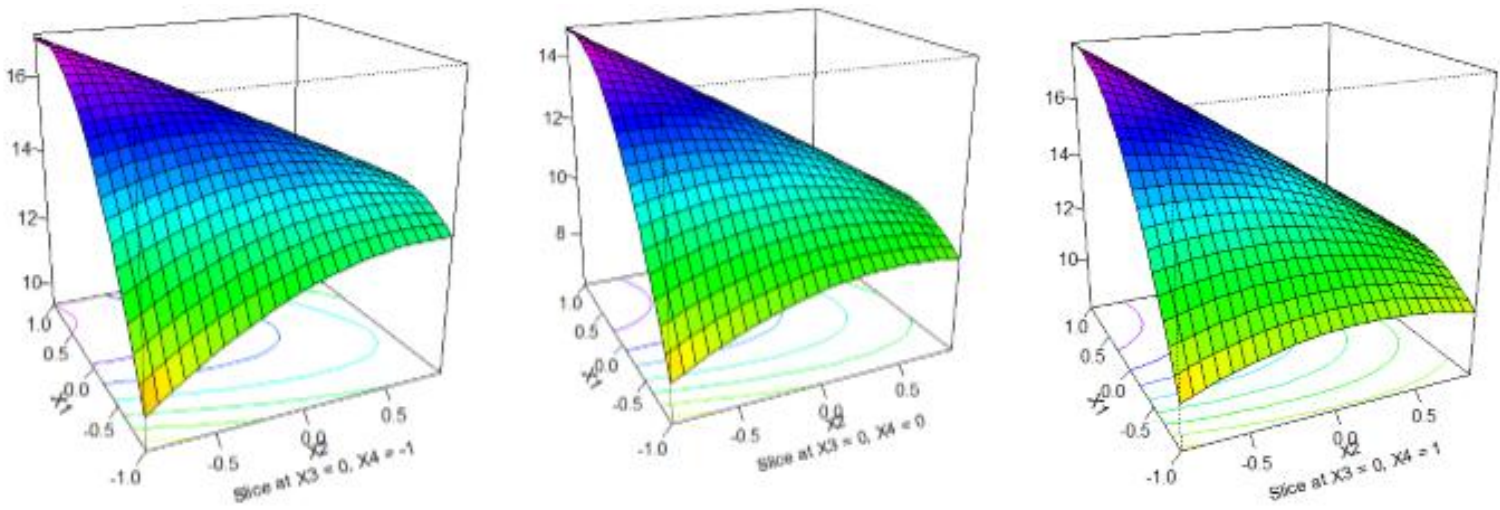

Figure 4. Effect of Egg White Level, Sorghum/Amaranth Ratio and Emulsifier Level on Color b* Parameter (at a Water Level of $36 \%$ )
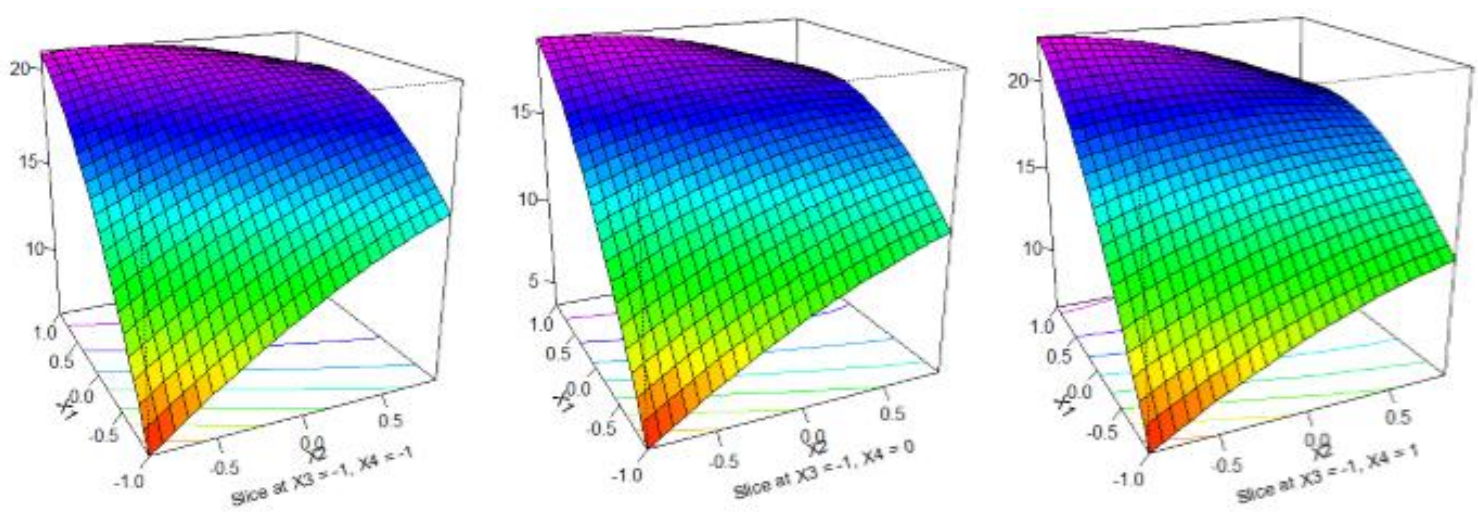

Figure 5. Effect of Egg White Level, Sorghum/Amaranth Ratio and Emulsifier Level on Color b* Parameter (at a Water Level of $33 \%$ ) 

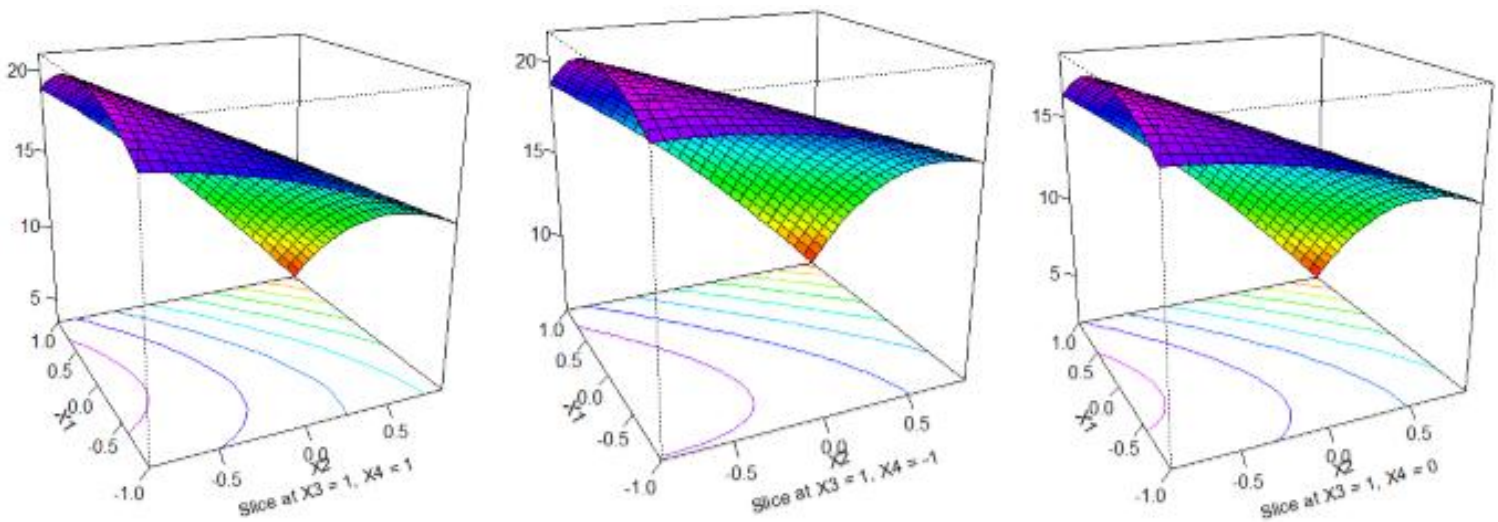

Figure 6. Effect of Egg White Level, Sorghum/Amaranth Ratio and Emulsifier Level on Color b* Parameter (at a Water Level of $39 \%$ )

According to the surface plots, the amount of water has a significant effect on the $b^{*}$ parameter whereas the emulsifier level has none. The maximal $b^{*}$ value was close to Barilla and Royal Quinoa values. $b^{*}$ value was maximal with a level of water of $33 \%$, a egg white level of $24 \%$ and a sorghum/amaranth ratio of $5 / 35 \%$. It was also maximal with a level of water of $39 \%$, a egg white level of $12 \%$ and a sorghum/amaranth ratio of 5/35\%.
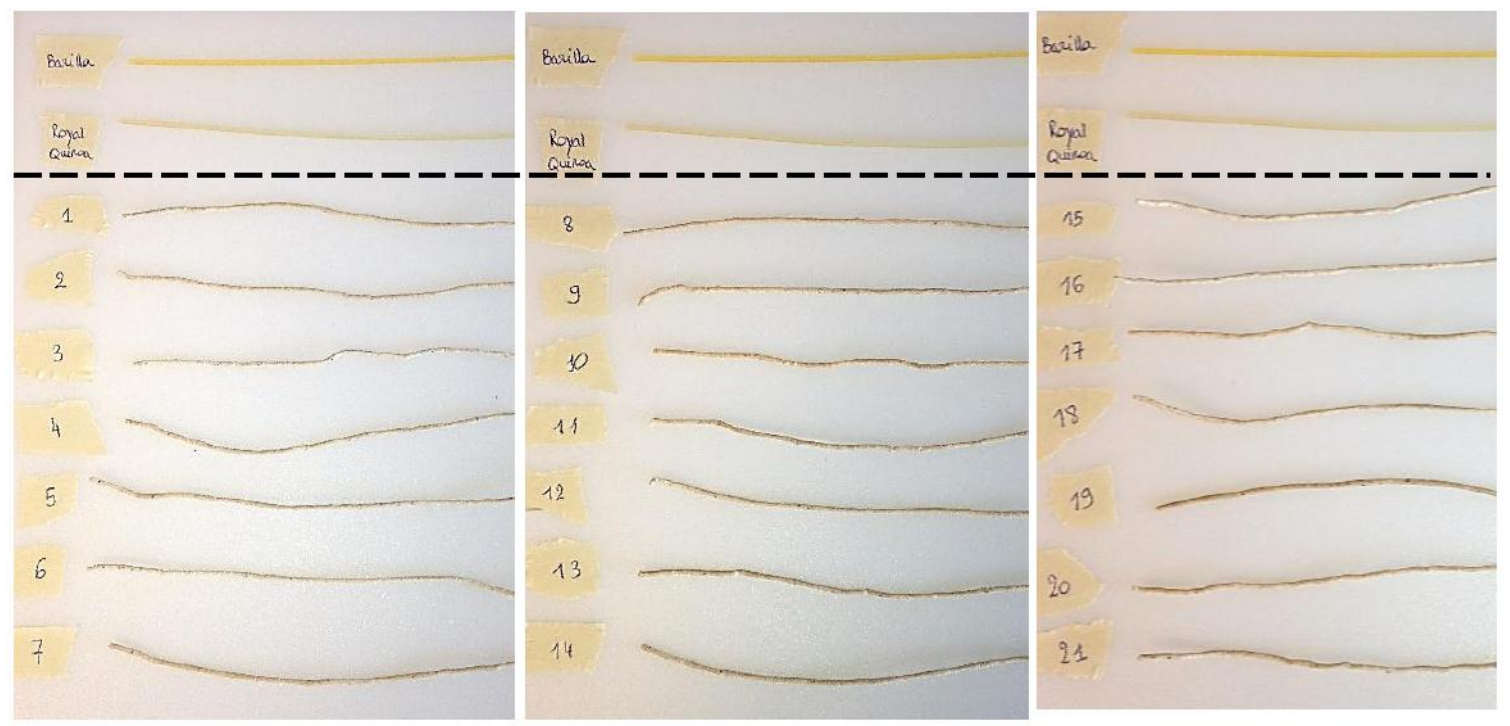

Figure 7. Photos of the Trial Pastas and the Two Reference Pastas (Barilla and Royal Quinoa)

\section{Unit density}

The pasta structure compactness is determinate during the pasta making process. Indeed, the density depends of the type of pasta (spaghetti, lasagna, etc.) and of the process used. Fardet et al. (1998) found that extruded pasta can be denser and their starch/protein network is tighter than in lasagna. 


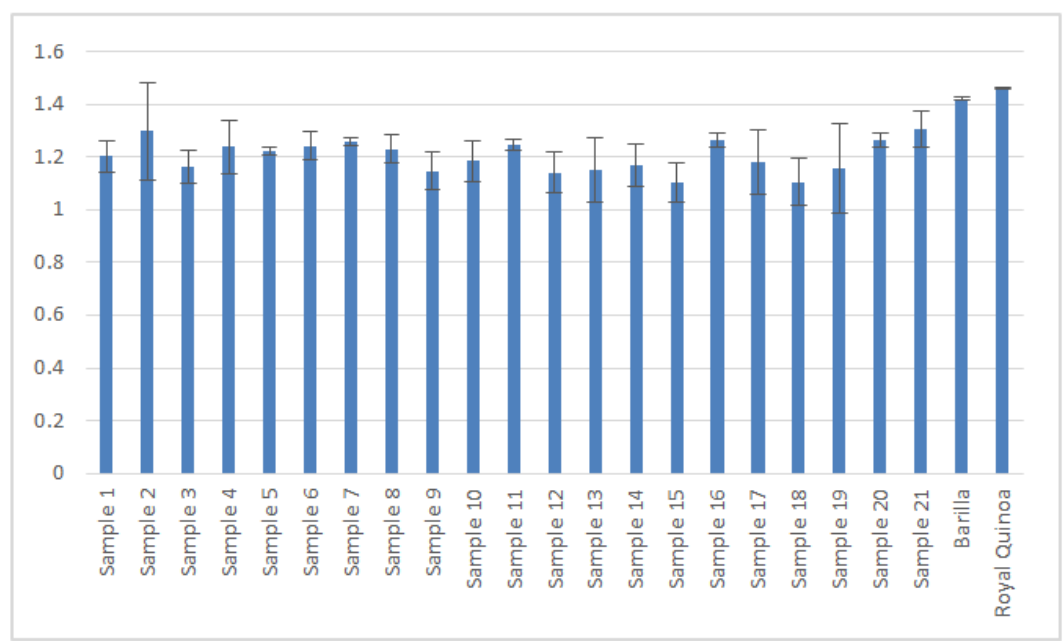

Figure 8. Unit Density of the Trial Pastas and the Reference Pastas (+/- 1 SD)

According to Figure 8, the density of Barilla and Royal Quinoa pasta was higher than the density of the trial pastas. It was more than $1400 \mathrm{~g} / \mathrm{cm}^{3}$ for the references and include between 1105 and $1306 \mathrm{~g} / \mathrm{cm}^{3}$ for the samples. This was certainly due to the difference of extrusion process. Indeed, the pastas were extruded using a Kitchen Aid Stand-Mixer Pasta Extruder Attachment and the references were extruded with industrial extruders.

The analysis of variance for density of pastas is presented in Table 4 . The predictive model developed for density was not considered adequate because of the unsatisfactory level of $\mathrm{R}^{2}$. Even though the model was not significant, explanatory analysis of data was performed in order to verify the tendency of this parameter.

Table 4. Analysis of Variance for Density of Pastas

\begin{tabular}{llllll}
\hline Response & Source & Df & Sum of squares & F value & $\mathrm{p}$ value \\
\hline \multirow{2}{*}{ Density } & Model & 4 & 0.0331 & 4.9014 & 0.1252 \\
\cline { 2 - 6 } $\mathrm{R}^{2}=0.525$ & Residual & 6 & 0.0101 & & \\
\cline { 2 - 6 } & Lack of fit & 6 & 0.0101 & & \\
\cline { 2 - 6 } & Pure error & 0 & 0.0000 & & \\
\hline
\end{tabular}

The analysis of variance determined that the sorghum/amaranth ratio, and the emulsifier amount had a significant effect on the density. Surface plots (not presented here) showed that pasta density was higher with a sorghum/amaranth ratio of 5/35, emulsifier level of $2.4 \%$, egg white level of $24 \%$ and water level of $33 \%$.

\section{Water activity}

The water activity is equivalent to the amount of reactive water available. It is a major parameter used to predict and control the food safety/stability during the transformation process and the storage (Palmade, 2015).

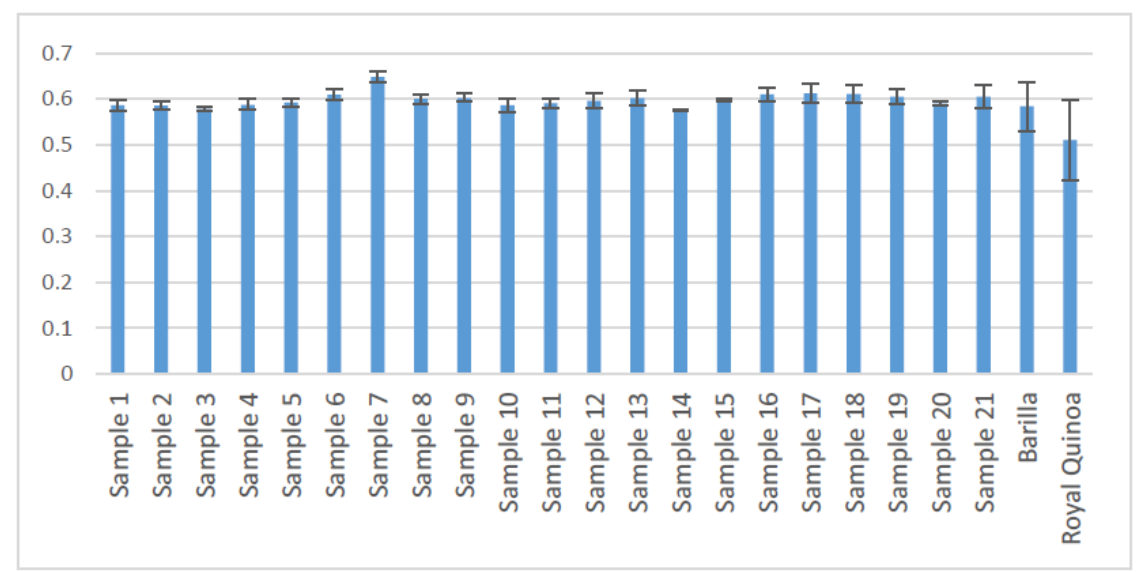

Figure 9. Water Activity $\left(a_{w}\right)$ of the Trial Pastas and the Reference Pastas (+/- 1 SD). 
As shown in Figure 9, the water activity varied between 0.57 and 0.65 for the trial pastas and the references. These values ensure the microbiologically safety of the products. Indeed, the microorganisms were unable to multiply at a water activity lower than 0.5 and only some yeasts can proliferate at an $\mathrm{a}_{\mathrm{w}}$ of 0.6 (Palmade, 2015).

The analysis of variance for water activity of pastas is presented in Table 5. The predictive model developed for water activity was acceptable but not satisfactory because of the low level of $\mathrm{R}^{2}$. Even though the model was not significant, explanatory analysis of data was performed in order to verify the tendency of this parameter. The model predicted that the egg white level and the sorghum/amaranth ratio were the two factors which have a significant effect on aw. The response surface models were plots and it was found that the lowest water activity was obtained with a maximal amount of egg white (24\%), a minimal ratio of sorghum/amaranth $(5 / 35 \%)$ and a level of water included between 33 and $36 \%$.

Table 5. Analysis of Variance for the Water Activity of Pastas

\begin{tabular}{llllll}
\hline Response & Source & Df & Sum of squares & F value & $\mathrm{p}$ value \\
\hline Water activity & Model & 4 & 0.0028 & 5.4366 & 0.0091 \\
& Residual & 15 & 0.0019 & & \\
\hline $\mathrm{R}^{2}=0.478$ & Lack of fit & 15 & 0.0019 & & \\
\hline & Pure error & 0 & 0.0000 & & \\
\hline
\end{tabular}

\section{Texture}

Texture is defined as the sensory response and the reaction of the food structure after a force action (Szczesniak, 1987). This is a critical parameter in the product acceptance by the consumers (Moskowitz \& Drake, 1972). Factors involved in pasta texture are the quality and quantity of proteins, the drying process, and the cooking parameters (cooking water, water absorption) (Matsuo et al., 1972; Manthey et al., 2004; Cunin et al, 1995). Indeed, the cooking water and the drying temperature impact the pasta adhesion (Smewing, 1997). Guan \& Seib also reported that the extrusion process affect the raw and cooked pasta texture (Guan, \& Seib, 1994). Several researchers have adopted firmness of raw pasta and stickiness of cooked pasta as main quality parameters for pasta (Raina et al., 2005). In this study, the firmness of raw pasta was analyzed.

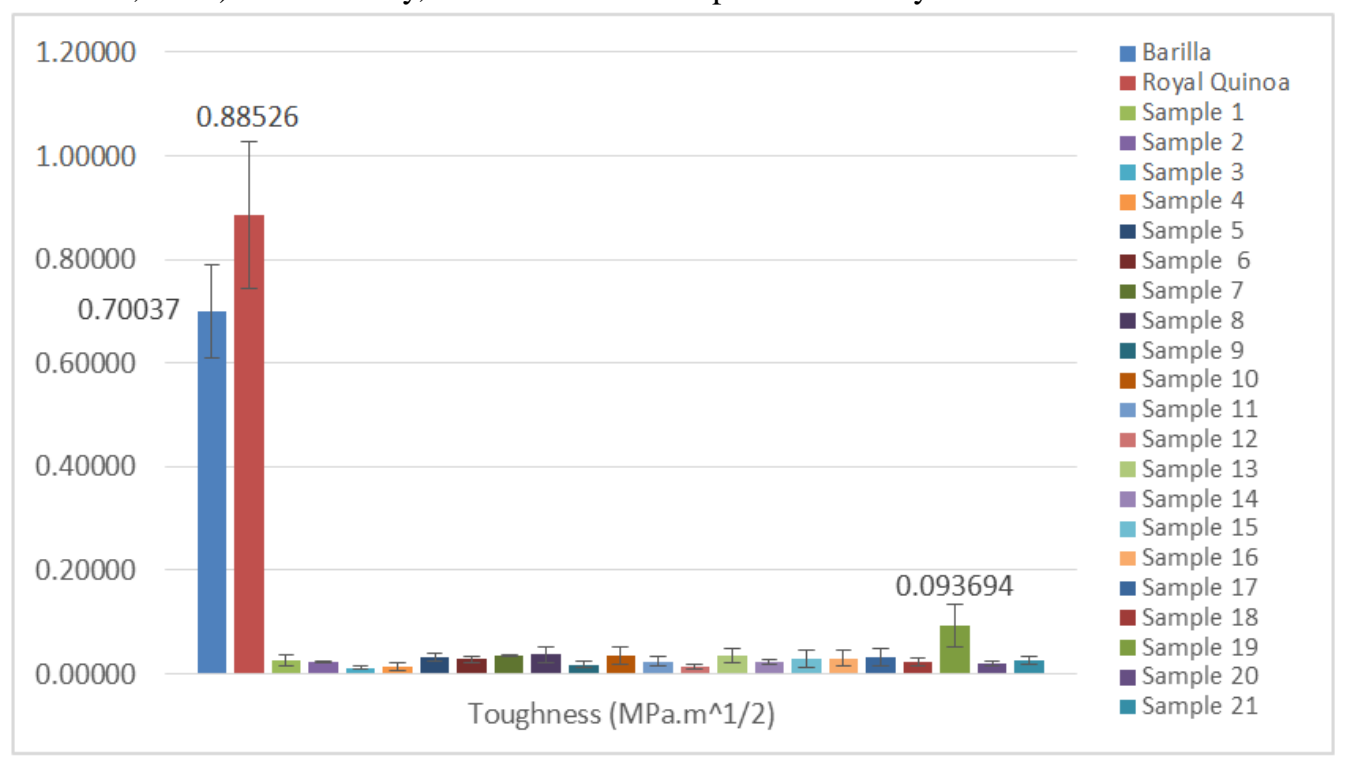

Figure 10. Toughness of the Trial Pastas and the Reference Pastas (+/- 1 SD)

The standard toughness value for classical pasta is $0.478 \mathrm{MPa} / \mathrm{m}^{1 / 2}$ (Guinea et al., 2004). The toughness value of industrial pasta Barilla and Royal Quinoa was close to this standard value (Figure 10), but the firmness values of the main trials were lower (Figure 11). Only the value of the 19th sample was a little higher, but was still too low. This means that all the sample were quite breakable, which will impact the consumer acceptance. 


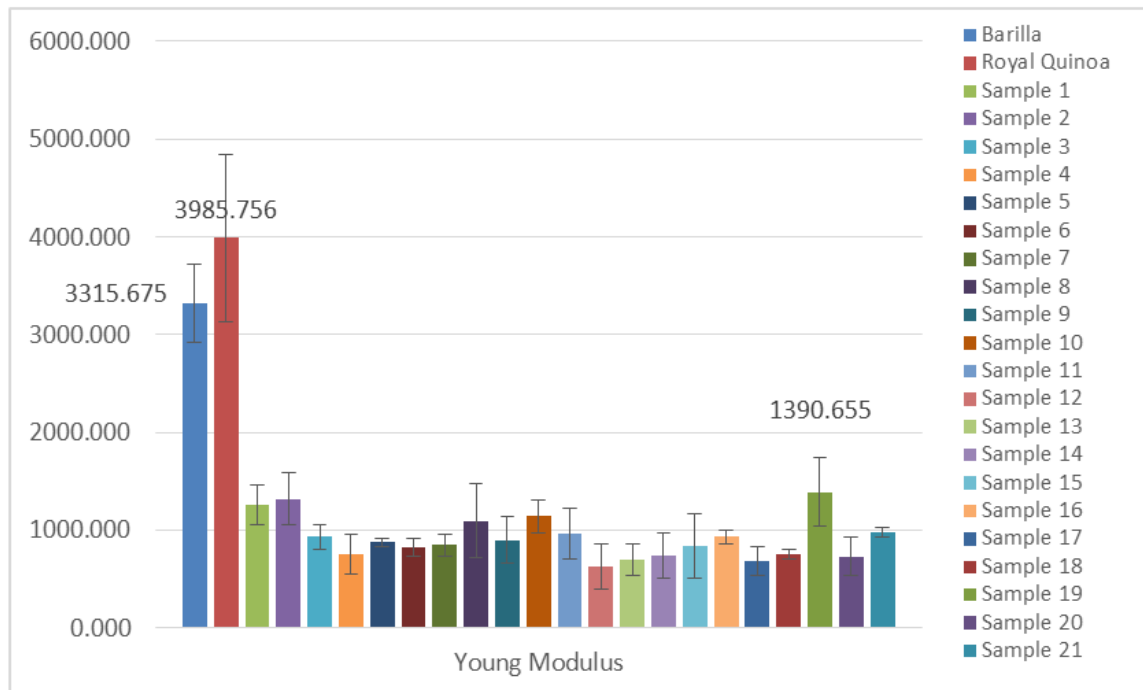

Figure 11. Young's Modulus of the Trial Pastas and the Reference Pastas (+/- 1 SD)

The young modulus is defined as the rate at which a deformed material returns to its original shape after a stressing force is removed. The young modulus of the reference pasta was higher than the value of the main trials. These results were correlated to the toughness value.

To study the factors involved in pasta texture, an analysis of variance (ANOVA) was carried out. Results are shown in Table 6.

Table 6. Analysis of Variance for Texture of Pastas

\begin{tabular}{llllll}
\hline Response & Source & Df & Sum of squares & F value & p value \\
\hline Firmness & Model & 4 & 0.0019 & 2.5126 & 0.0878 \\
& Residual & 13 & 0.0024 & & \\
\hline $\mathbf{R}^{\mathbf{2}=\mathbf{0 . 3 2 0}}$ & Lack of fit & 12 & 0.0024 & & \\
\hline & Pure error & 0 & 0.0000 & & \\
\hline Elasticity & Model & 4 & 129625 & 0.7240 & 0.4476 \\
\hline & Residual & 12 & 537136 & & \\
\hline $\mathbf{R}^{\mathbf{2}=\mathbf{0 . 0 2 3}}$ & Lack of fit & 12 & 537136 & & \\
\hline & Pure error & 0 & 0 & & \\
\hline
\end{tabular}

The predictive model developed for young modulus (elasticity) was really too low and was not suitable to be analyzed. The predictive model for toughness was not adequate either because of the low value of $\mathrm{R}^{2}$, even though, explanatory analysis of data was performed and surface plots (Figures 12, 13, 14) were generated to describe the quality response of the egg white and emulsifier level, which were the two parameters that had significant effects on toughness.
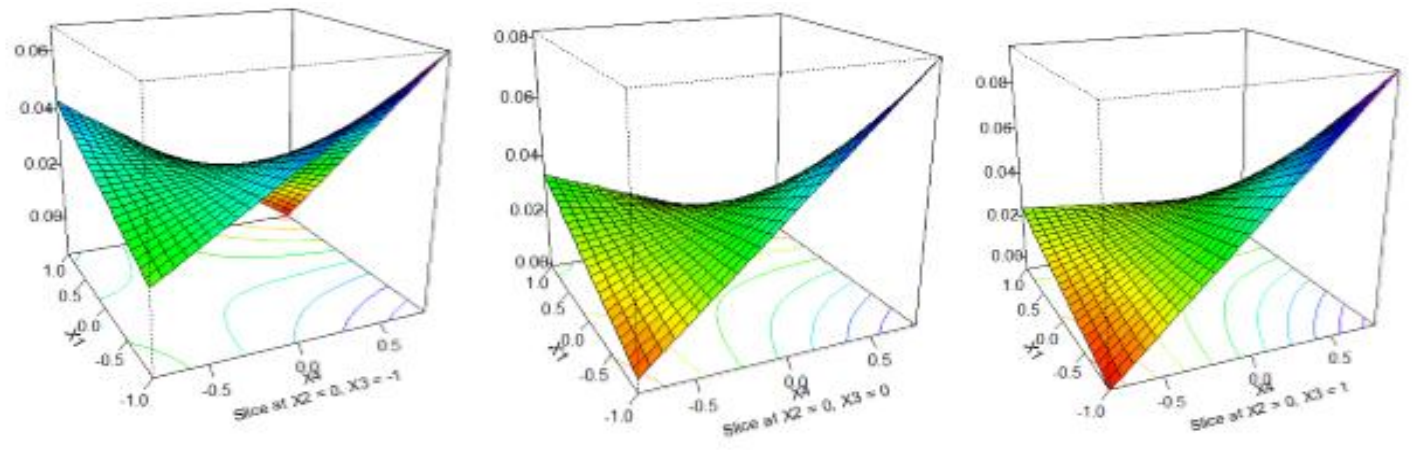

Figure 12. Effect of Egg White Level, Emulsifier Level and Water Level on Toughness (at a Sorghum/Amaranth Ratio of 20/20) 

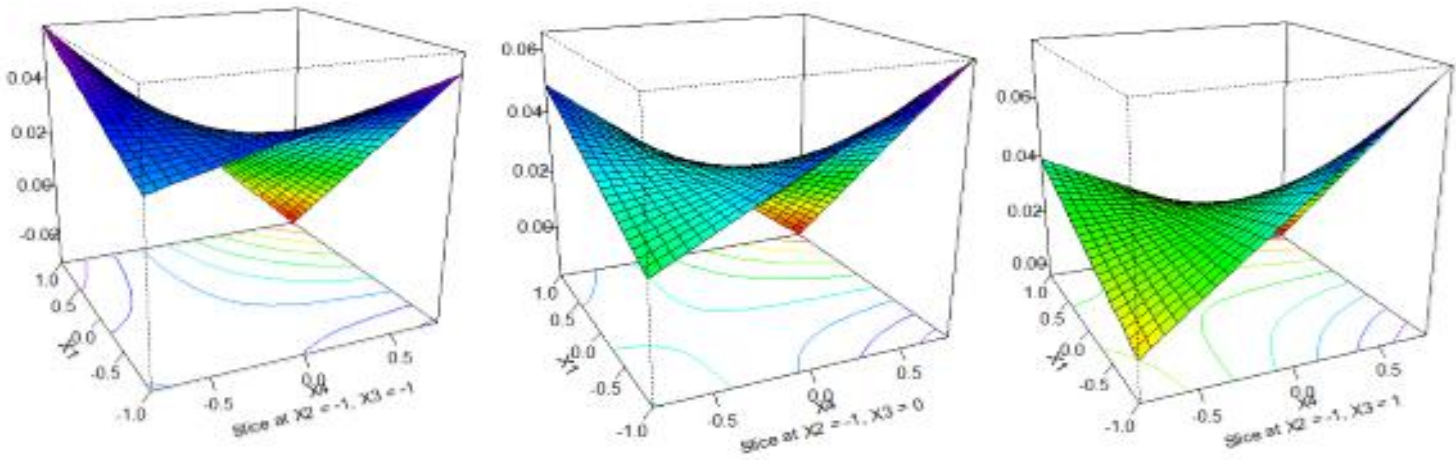

Figure 13. Effect of Egg White Level, Emulsifier Level and Water Level on Toughness (at a Sorghum/Amaranth Ratio of 5/35)
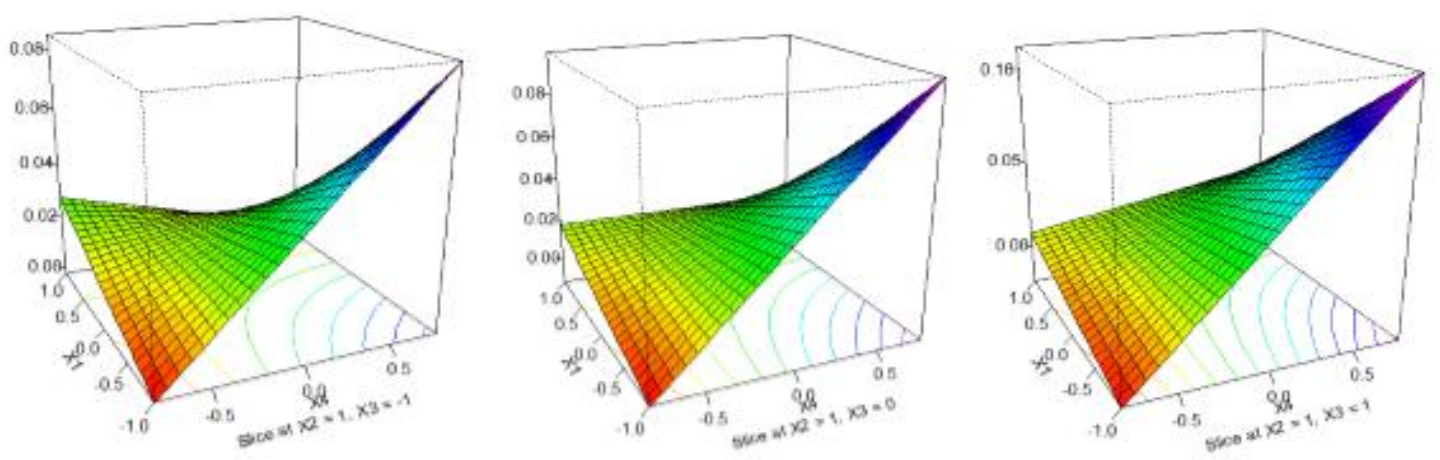

Figure 14. Effect of Egg White Level, Emulsifier Level and Water Level on Toughness (at a Sorghum/Amaranth Ratio of 35/5)

According to the surface response plots, sorghum / amaranth ratio has a significant effect on the pasta firmness. The level of water has an effect too, but less significant. A maximal toughness value is critical to have strong pasta. This maximal value was obtained with a maximal emulsifier level $(2.4 \%)$ and water level (39\%), a minimal egg white amount $(0 \%)$ and a sorghum/ amaranth ratio of $35 / 5$.

\subsection{Functional Properties}

During cooking, pasta undergoes complex modifications caused by heating and water uptake that determine different effects both at the macroscopic and molecular levels. In traditional pasta made with durum wheat semolina, cooking induces starch gelatinization with partial disappearance of the crystalline zones of amylopectin, the leaching of amylose together with other soluble substances into the cooking water, and the contemporaneous coagulation of the gluten network.

A completely different situation occurs in gluten-free pasta: the viscoelastic gluten network is absent, and the intensive heating applied during the different technological steps involved in pasta production has given rise to important modifications to the starch organization, leading to the creation of a new structure formed by retrograded or partially gelatinized and retrograded starch; during cooking, the extent of starch gelatinization increases and, at the same time, a denaturation of the proteins contained in the different raw materials takes place (Lucisano et al., 2012).

\section{Cooking time}

Optimum cooking time is the time needed to cook the entire core of the pasta. It is related to density of extruded spaghetti. Indeed, it has been reported that low pasta density are related to short optimum cooking time. Spaghetti with low density have a less tightly proteins network, which provide a path for water absorption into pasta, which resulted in shorter cooking times (Manthey et al., 2004). The optimal cooking time for the 21 samples was between 7 and 8.5 minutes, whereas it was 14 minutes for Barilla pasta and 17.5 minutes for Royal Quinoa pasta. There was a significant difference between the samples and the references, probably due to the difference of density. But these cooking time were satisfactory because a study reported that too long cooking 
time damaged the spaghetti quality especially for gluten free pasta (Grzybowski \& Donnelly, 1979).

Table 7. Analysis of Variance for Optimal Cooking Time of Pastas

\begin{tabular}{llllll}
\hline Response & Source & Df & Sum of squares & F value & $\mathrm{p}$ value \\
\hline Cooking time & Model & 4 & 1.8000 & 3.2727 & 0.1744 \\
& Residual & 6 & 0.8250 & & \\
\hline $\mathrm{R}^{2}=0.45$ & Lack of fit & 6 & 0.8250 & & \\
\hline & Pure error & 0 & 0.0000 & & \\
\hline
\end{tabular}

The predictive model (Table 7) developed for optimal cooking time was acceptable. Explanatory analysis of data was performed and it was found that emulsifier level was the only parameter that had a significant effect on the cooking time. The higher the level of guar gum, the longer the optimal cooking time.

\section{Cooking weight}

Another important measured index is pasta water uptake (Figure 15), which depends on the weakness of starch granules and is related to the amount of starch damage (Lucisano et al., 2012). It is related to the cooking time too: longer cooking times induced an even more marked weight increase.

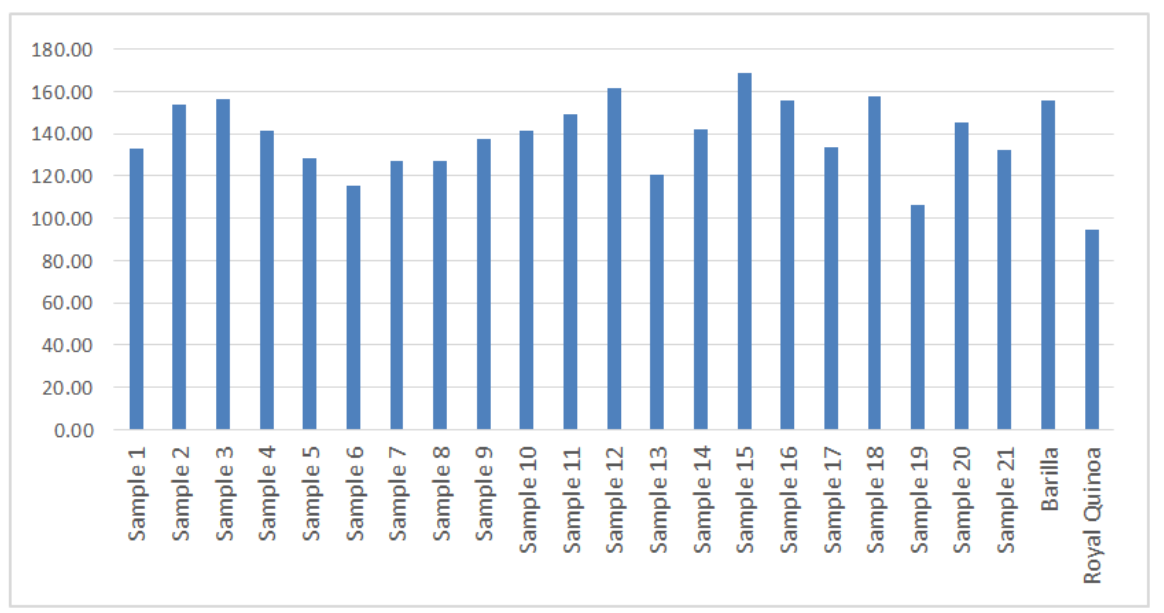

Figure 15. Water Absorption (\%) in the Trial Pastas and the Reference Pastas (+/- 1 SD)

The water absorption of Barilla pasta was almost equal to the 2, 3, 16 and 18 samples. On the other hand, the water absorption of Royal Quinoa pasta was the lowest and was probably due to the difference of composition. Indeed a study found that the water absorption in pasta is related to the kind of flour which is used (Adekunle Ayo, 2007). The predictive models developed for water absorption (Table 8) was considered adequate because it possessed a non-significant lack of fit and had satisfactory levels of $\mathrm{R}^{2}$.

Table 8. Analysis of Variance for Water Absorption of the Pastas

\begin{tabular}{llllll}
\hline Response & Source & Df & Sum of squares & F value & $\mathrm{p}$ value \\
\hline Water absorption & Model & 4 & 3274.7 & 12.796 & 0.00243 \\
& Residual & 10 & 639.8 & & \\
\hline $\mathrm{R}^{2}=0.751$ & Lack of fit & 10 & 639.8 & & \\
\hline & Pure error & 0 & 0.0000 & & \\
\hline
\end{tabular}

The significant variables affecting this response were the egg white and emulsifier level, and the interaction egg white amount and water level. A maximal water absorption was linked to a maximal amount of egg white (2.4\%) and a minimal emulsifier level.

\section{Cooking loss}

During the cooking, some parts of the noodles dissolve in the water: soluble solids leach out from the pasta and pass into the cooking water. This phenomenon proceeds to different extents in relation to the structural compactness of the sample. The better the protein network is developed, the smaller the cooking loss. The loss of 
solids, in fact, traditionally represents a measure of pasta quality, expressing its resistance to disintegration upon boiling: low amounts of solids into the cooking water indicate a high pasta cooking quality (Pagani et al., 2007). The cooking loss can also be increased by the composition of altering the cooking water: the higher the calcium and magnesium in the water, the more the spaghetti will be sticky and the cooking loss high (Dexter et al., 1983). However, unlike durum wheat pasta, due to the lack of gluten, the characteristics of gluten free pasta in general depend heavily upon the functional properties of the starch: it undergoes different heat treatments during processing, and often functions as the only structural network of the final gluten free product (Lucisano et

al., 2012).

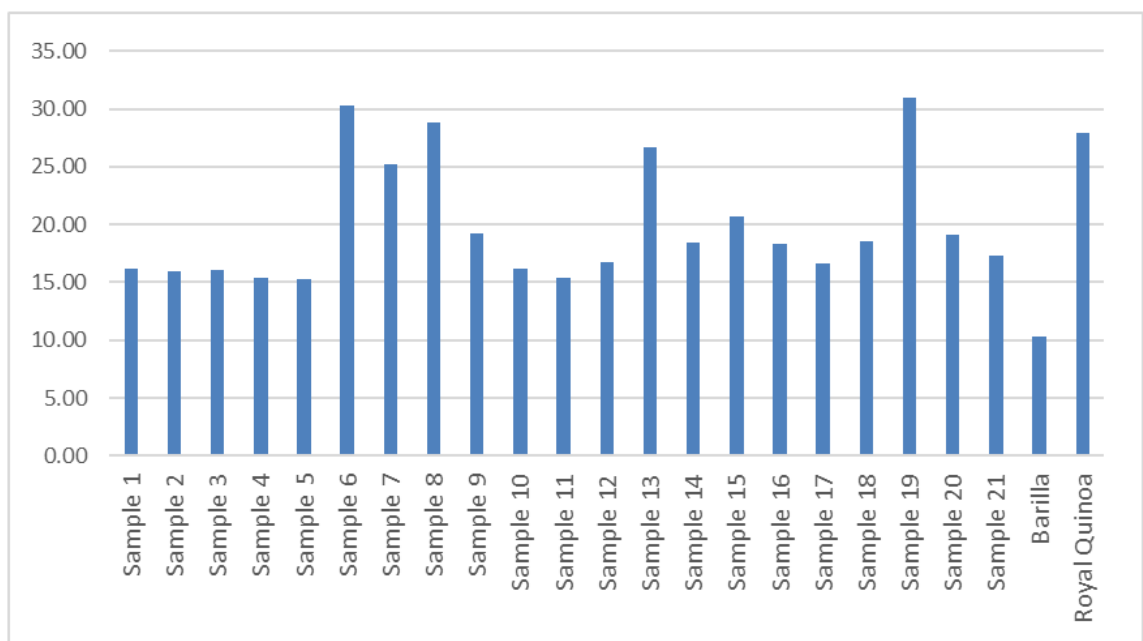

Figure 16. Cooking Loss (\%) in the Trial Pastas and the Reference Pastas (+/- 1 SD)

The lowest cooking loss (Figure 16) was associated with the Barilla pasta. The Royal Quinoa pasta had a very high percentage of cooking loss. The 1, 2, 3, 4, 5 and 11 samples lost less matter during cooking compared to all the other experimental design samples.

The analysis of variance for cooking loss of pastas is presented in Table 9. The predictive model developed for cooking loss was considered adequate because it possessed a non-significant lack of fit and had satisfactory levels of $\mathrm{R}^{2}$, and model significance.

Table 9. Analysis of Variance for Cooking Loss of Pastas

\begin{tabular}{llllll}
\hline Response & Source & Df & Sum of squares & F value & $\mathrm{p}$ value \\
\hline Cooking loss & Model & 4 & 363.3 & 12.6088 & 0.0299 \\
& Residual & 6 & 43.22 & & \\
\hline $\mathrm{R}^{2}=0.733$ & Lack of fit & 6 & 43.22 & & \\
\hline & Pure error & 0 & 0.000 & & \\
\hline
\end{tabular}

The significant variables affecting the cooking loss parameter were the amount of egg white and the interaction between the amount of egg white and the emulsifier level. Surface plots were generated to describe the quality response of these parameters. According to the plots (Figures 17, 18 and 19), sorghum/ amaranth ratio has no significant effect on cooking loss, whereas water level has a great effect. As mentioned previously, good quality pasta are pasta with low cooking loss. In order to reduce as much as possible the cooking loss, it is required to have a maximal egg white and emulsifier level and an amount of water included between 33 and $36 \%$. The effect of emulsifier on cooking loss was previously demonstrated by Nazarov. He found that mono- and diglycerides of fatty acids form complexes with amylose, thereby preventing the passage of starch into the cooking water, reducing cooking loss and stickiness (Nazarov, 1977). 

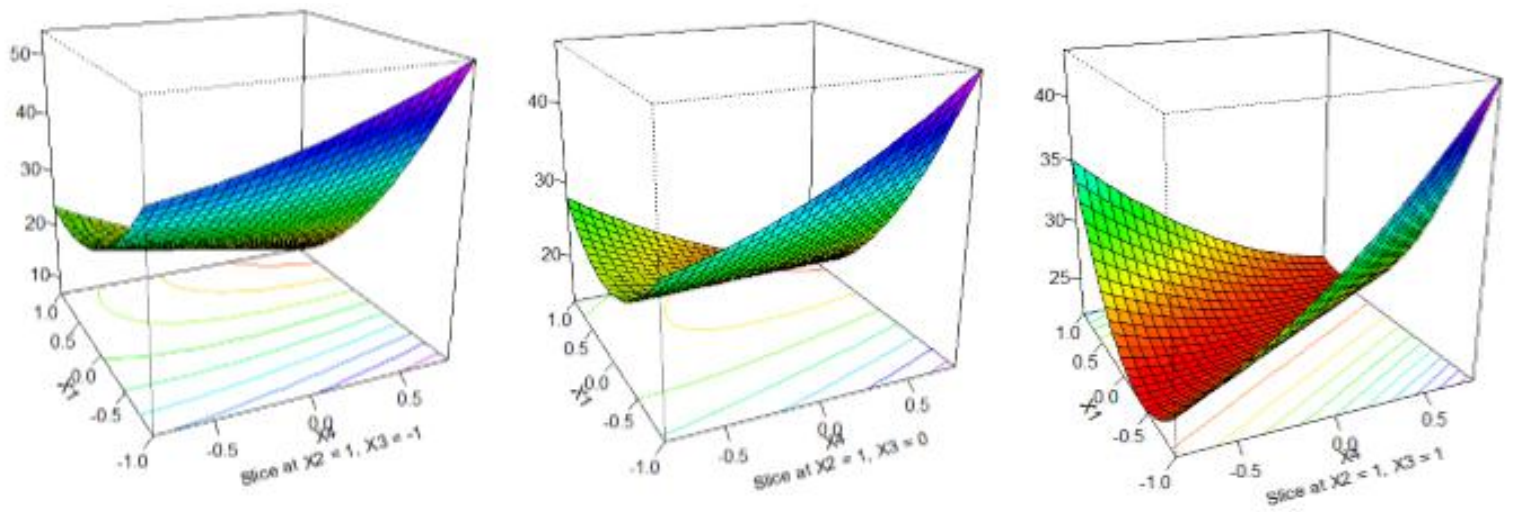

Figure 17. Effect of Egg White Level, Emulsifier Level and Water Level on Cooking Loss (at a Sorghum/Amaranth Ratio of 20/20)
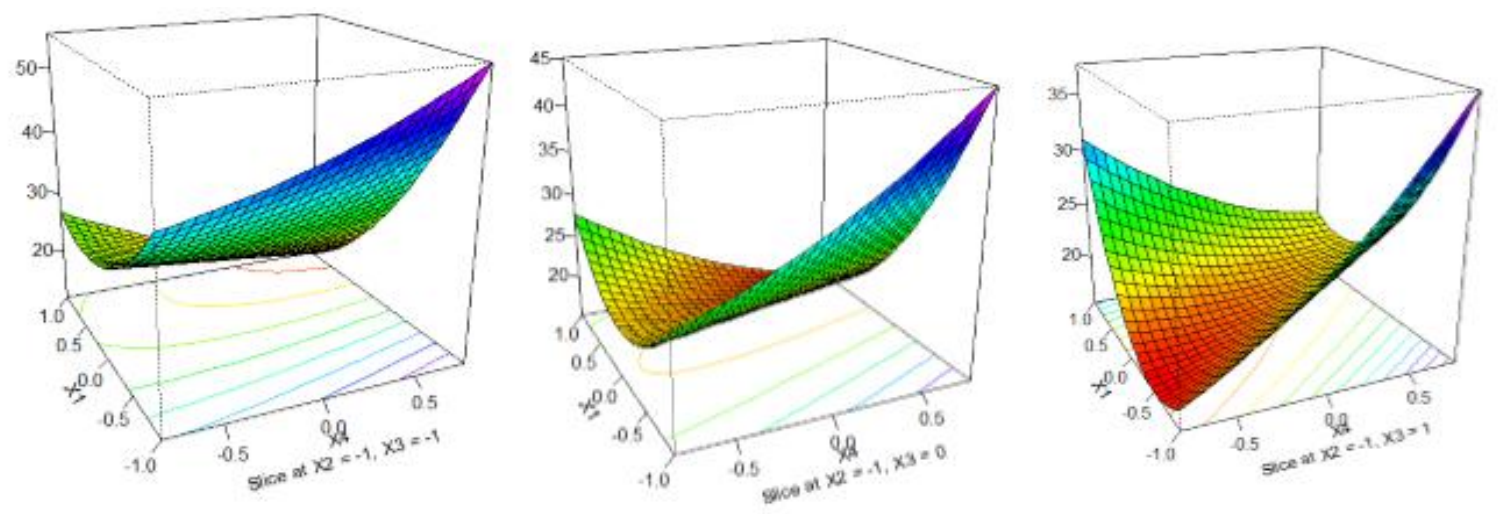

Figure 18. Effect of Egg White Level, Emulsifier Level and Water Level on Cooking Loss (at a Sorghum/Amaranth Ratio of 5/35)
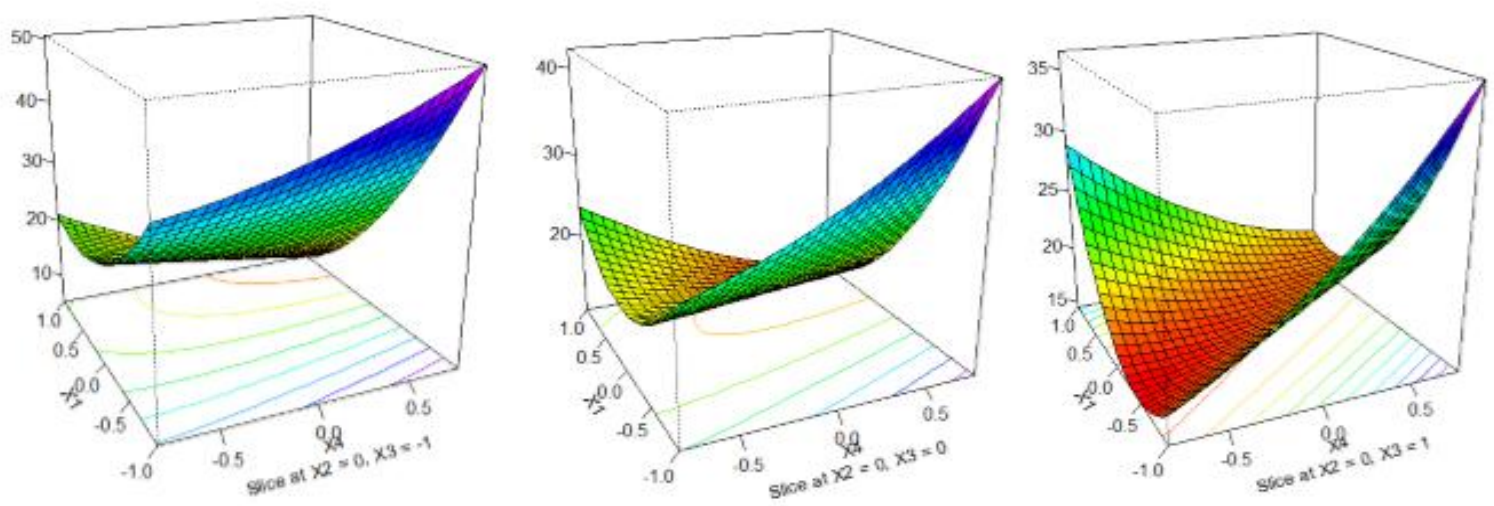

Figure 19. Effect of Egg White level, Emulsifier Level and Water Level on Cooking Loss (at a

Sorghum/Amaranth Ratio of 35/5)

The cooking loss can also be reduced if the drying conditions are modified. Manthey et al. (2004) reported that high temperature drying strengthens the gluten matrix, which protects starch granules from rupturing during cooking. Indeed, ultrahigh temperature drying denatures proteins associated with the gluten matrix, which subsequently protects starch granules from rupturing during cooking. Furthermore, it reduces water permeability and causes small changes in the packing and arrangement of starch granules, contributing to decreased cooking loss and increased cooked firmness (Vansteelandt \& Delcour, 1998). 


\subsection{Determination of the Optimal Formulation}

The optimal formulation was determined using the best formulation of the major parameter such as cooking loss, firmness, color and density. As shown in Table 10, the egg white level for the optimal formulation was $\mathbf{1 2} \%$ to have an intermediate value between cooking loss and toughness. Sorghum/amaranth ratio selected was $\mathbf{3 0 / 1 0}$ to diversify the flour, the water level choose was $\mathbf{3 6} \%$ because beyond this level, the cooking losses were too high, and the best emulsifier level for the majority of analyses were $\mathbf{2 . 4} \%$. After the optimal formulation was manufactured into pasta, it was then subjected to the same physical and quality analyses, conducted in triplicate, and the results are shown below in Table 11.

Table 10. Optimum Formulation of Each Parameter

\begin{tabular}{ccccc}
\hline & Egg white level & Sorghum/ amaranth ratio & Water level & Guar gum level \\
\hline Cooking loss & $24 \%$ & No effect & $33 \%$ & $2.4 \%$ \\
& & $35 \%$ & No effect & $2.4 \%$ \\
\hline Toughness & $0 \%$ & $5 / 35$ & $39 \%$ & $2.4 \%$ \\
\hline $\mathrm{b}^{*}$ & $12 \%$ & $35 / 5$ & $39 \%$ & No effect \\
\hline $\mathrm{a}^{*}$ & $24 \%$ & $35 / 5$ & $33 \%$ & $1.2 \%$ \\
\hline $\mathrm{L}^{*}$ & $24 \%$ & $5 / 35$ & $33 \%$ & $2.4 \%$ \\
\hline Density & $24 \%$ & & & \\
\hline
\end{tabular}

Table 11. Results of Analysis for the Optimal Pastas (+/- 1 SD)

\begin{tabular}{lcc}
\hline Moisture content $(\%)$ & $12.63 \pm 0.23$ \\
\hline Water activity & & $0.549 \pm 0.003$ \\
\hline Density $\left(\mathrm{g} / \mathrm{cm}^{3}\right)$ & & $1.27 \pm 0.05$ \\
\cline { 2 - 3 } & $\mathrm{L}^{*}$ & $60.40 \pm 0.25$ \\
\cline { 2 - 3 } Color & $\mathrm{a}^{*}$ & $3.56 \pm 0.12$ \\
\cline { 2 - 3 } & $\mathrm{b}^{*}$ & $15.58 \pm 0.45$ \\
\cline { 2 - 3 } & $\Delta \mathrm{E}$ & $58.79 \pm 0.48$ \\
\hline Optimal cooking time $(\mathrm{min})$ & $9 \pm 0$ \\
\hline Cooking loss $(\%)$ & $17.37 \pm 0.55$ \\
\hline Water absorption $(\%)$ & $147.85 \pm 2.48$ \\
\hline Toughness $\left(\mathrm{MPa} / \mathrm{m}^{1 / 2}\right)$ & $0.056 \pm 0.02$ \\
\hline Young modulus & $1321.8 \pm 389.9$ \\
\hline
\end{tabular}

The value of density, water activity, color, water absorption and optimal cooking time of the optimal pasta were as good as expected. However, the cooking loss was acceptable but could be lower, and the texture was too breakable. The problem was that the cooking losses were the lowest when the egg white level was maximum (24\% or more) while the firmness was maximal when the egg white level was null $(0 \%)$. Thus there was a contradiction between the two major parameters. A compromise was chosen in the optimal formulation (12\% egg white), which explain the no optimal value of toughness and cooking loss could be achieved.

\subsection{Sensory Analysis}

For all consumer parameters (Figure 20), except odor, optimal pastas had lower scores than Barilla and Royal Quinoa Pasta. The two most important parameters have the lower scores: taste was marked 2.6/5 and the texture 2.5/5. The panelists were also asked to explain why they liked or disliked the pastas. Among the comments, it was often said that the texture was too granular and crumbly. The appearance was correct, the color similar to whole pasta, and the odor was pleasant. But the texture was the major reason for low acceptance of the pastas. 


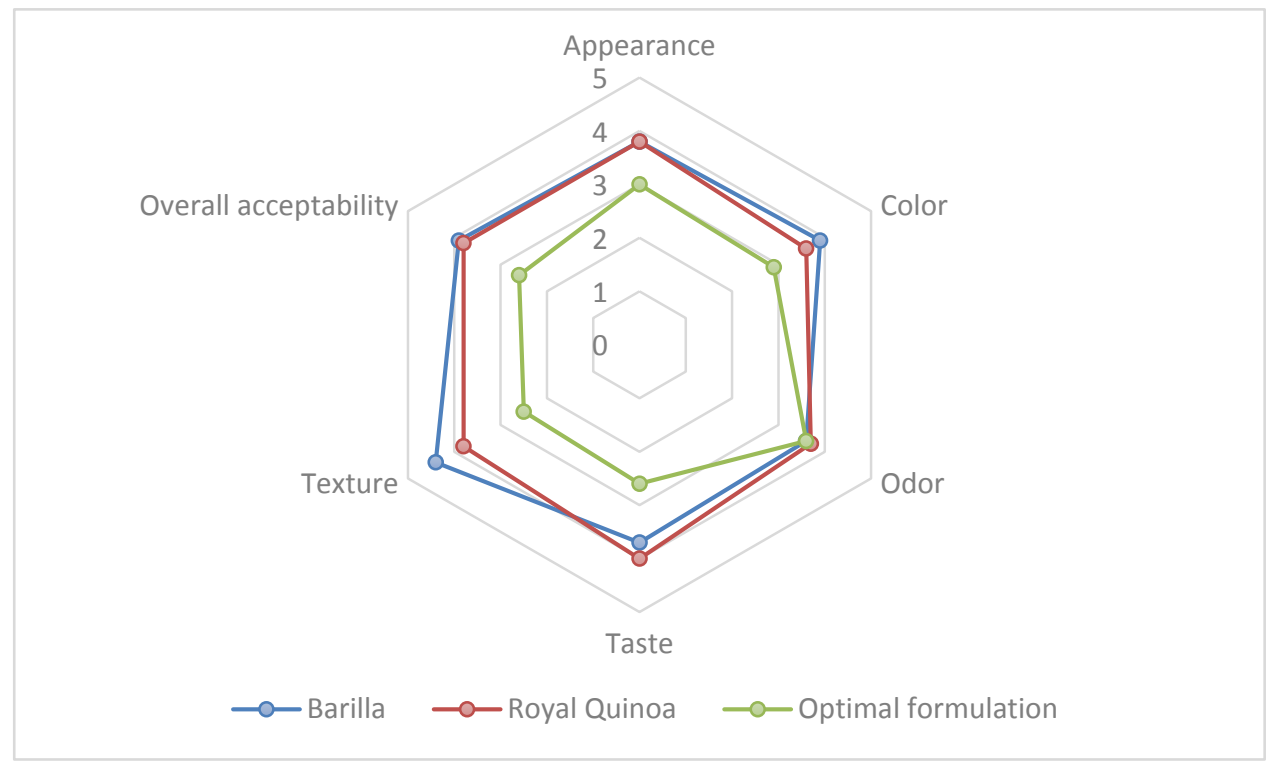

Figure 20. Sensory Analysis Results

In the second part, the panelists classified in order of preference the three different pastas, without sauce and with sauce (Tables 12 and 13).

Table 12. Results of the Ranking Test Without Sauce

\begin{tabular}{lllll}
\hline & $\mathbf{1}$ & $\mathbf{2}$ & $\mathbf{3}$ & $\mathbf{R}$ \\
\hline Barilla & $0 \%$ & $40 \%$ & $60 \%$ & 26 \\
Royal Quinoa & $10 \%$ & $60 \%$ & $30 \%$ & 22 \\
\hline Optimal pasta & $90 \%$ & $0 \%$ & $10 \%$ & 12 \\
\hline
\end{tabular}

Table 13. Results of the Ranking Test with Sauce

\begin{tabular}{lllll}
\hline & $\mathbf{1}$ & $\mathbf{2}$ & $\mathbf{3}$ & $\mathbf{R}$ \\
\hline Barilla & $0 \%$ & $30 \%$ & $70 \%$ & 27 \\
Royal Quinoa & $10 \%$ & $70 \%$ & $20 \%$ & 21 \\
\hline Optimal pasta & $90 \%$ & $0 \%$ & $10 \%$ & 12 \\
\hline
\end{tabular}

It appeared that $60 \%$ of the panelist liked the Barilla pasta most, without sauce, and $70 \%$ like the Barilla pasta most, with sauce. Only $10 \%$ of the judges prefer the formulated pasta with and without sauce.

In order to know if the products were classified significantly differently or not, a Friedman test was applied. The Fr value was calculated as following:

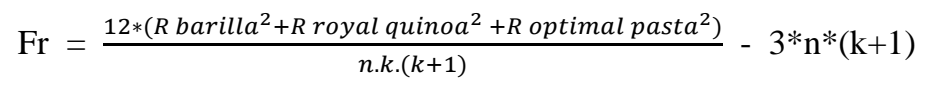

With $\mathrm{R}$ the sum of the ranks, $\mathrm{n}$ le number of judge (10) and $\mathrm{k}$ the number of products tested (3)

$$
\mathrm{Fr}_{\text {test without sauce }}=10.4 \text { and } \mathrm{Fr}_{\text {test with sauce }}=11.4
$$

According to the Friedman Table, with $\mathrm{k}=3$ and $\mathrm{n}=10, \mathbf{F o}=\mathbf{9 . 6}$ with a risk of $1 \%$ that the difference was not significant.

For the two different tests, without and with sauce, $\mathrm{Fr}>\mathrm{Fo}$, so the hypothesis Ho (the products are not classified differently) was rejected and the three kinds of pastas were classified significantly differently. The consumers preferred Barilla industrial pasta.

\section{Conclusions}

In this study, response surface methodology, using Doehlert experimental design, was successfully used to identify the optimal formulation for egg pasta from maize, sorghum and amaranth flours. Varied trials were 
carried out on the 21 experimental design samples. Results were compared to two commercial gluten free pastas which were used as reference.

Water activity, density, water absorption and density of main trials were shown to be comparable to the industrial gluten-free pasta. The values of the other studied parameters were significantly different from the references. The experimental design pastas were breakable, their optimal cooking time was lower, the color was different and the cooking losses were higher. Analysis of variance (ANOVA) showed which effect had the different factors (egg white, water, emulsifier and flours) on the different parameters (e.g., cooking loss, density, water activity).

The moisture contents for experimental pastas were higher than the reference pastas. None of the factors had an effect on it, according to analysis of variance, but impacted by the drying process. Previous studies showed that the drying process had major effects on pastas quality. A high temperature drying increases firmness and reduces cooking loss.

The optimal formulation for our trials was chosen according to the response surface plots, in order to develop good quality pastas, with low cooking loss, high firmness, similar color as the references, and high density. Optimal conditions were $12 \%$ egg white, 30\%/10\% sorghum/amaranth ratio, $36 \%$ water, and $\mathbf{2 . 4 \%}$ emulsifier. However, this led to low firmness and cooking loss. A way to increase the pastas firmness, other than formulation changes, could be to use a different extrusion process.

Finally, sensory aspects of the final product were analyzed by a consumer panel to determine if the product could be appreciated by consumers or not. The overall acceptability was scored as 2.6/5 for our formulated pastas. Our products presented good nutritional values, color was appreciated, but texture was too granular and crumbly, which did the consumers not like. Barilla pasta, made with rice and maize flour, was the most appreciated by the panelists according to the ranking test. The Friedman test showed that these pastas were classified significantly differently.

Indeed, while we were able to produce viable pastas from our formulations, further work is needed before they can be implemented commercially. Texture and flavor must be improved. These should be targets for the next stages of research.

\section{References}

AACC International (2000). Method 66-50 Pasta and Noodle Cooking Quality - Firmness Method. In: Approved Methods of Analysis, 9th Ed. AACC International: St. Paul, MN, USA.

AACC International (2000). Method 44-19 Moisture-Air-Oven Methods. In: Approved Methods of Analysis, 9th Ed. AACC International: St. Paul, MN, USA.

AACC International (2000). Method 14-22 Color of Pasta-Reflectance Colorimeter Method. In: Approved Methods of Analysis, 9th Ed. AACC International: St. Paul, MN, USA.

Adekunle Ayo, J. (2007). The effect of amaranth grain flour on the quality of bread. International Journal of Food Properties, 4(2), 341-351.

Antognelli, C. (1980). The manufacture and applications of pasta as a food and as a food ingredient. $J$ Food Technology, 15(2), 125-145.

Broz, R., \& Horne, T. (2007). Gluten Free Product Development. CFW Column Product Development, 52(3).

Ciacci, C., Maiuri, L., Caporaso, N., Bucci, C., Del Giudice, L., Rita Massardo, D., Pontieri, P., Di Fonzo, N., Bean, R., Iorger, B., \& Londei, M. (2007). Celiac disease: In vitro and in vivo safety and palatability of wheat-free sorghum food products. Clinical Nutrition, 26(6), 799-805.

Cunin, C., Handschin, S., Walther, P., \& Escher, F. (1995). Structural changes in starch during cooking of durum wheat pasta, Lebensm.-Wiss. Technol., 28, 323-329.

Dexter, J. E., Matsuo, R. R., \& Morgan, B. C. (1983). Spaghetti Stickiness: Some Factors Influencing Stickiness and Relationship to Other Cooking Quality Characteristics. Journal of Food Science, 48(5), 1545-1551.

FAO. (1992). Le maïs dans la nutrition humaine, Produit par le département de l'agriculture, France. Retrieved from http://www.fao.org/docrep/t0395f/T0395F03.htm.

FAO. (1995). Le sorgho et les mils dans la nutrition humaine, Produit par le département de l'agriculture, France. Retrieved from http://www.fao.org/docrep/t0818f/T0818F08.htm.

Fardet, A., Hoebler, C., Baldwin, P. M., Bouchet, B., Gallant, D. J., \& Barry, J. L. (1998). Involvement of the protein network in the in vitro degradation of starch from spaghetti and lasagna: a microscopic and enzymic 
study. Journal of Cereal Science, 27, 133-145.

Feillet, P., \& Dexter, J. E. (1996). Quality requirements of durum wheat for semolina milling and pasta production, Monograph on Pasta and Noodle Technology, Saint Paul, MN; USA: AACC - American Association of Cereal Chemists, 95-131. Retrieved from http://prodinra.inra.fr/record/137270.

Fuad, T., \& Prabhasankar, P. (2010). Role of ingredients in pasta product quality: a review on recent developments. Critical Reviews in Food Science and Nutrition, 50, 787-798.

Inglett, G. E., Chen, D., \& Liu, S. X. (2015) Antioxidant activities of selective gluten free ancient grains. Food and Nutrition Sciences, 6, 612-621.

Guan, F., \& Seib, P. A. (1994). Instrumental probe and method to measure stickiness of cooked spaghetti and noodles. Cereal Chemistry, 71, 330-335.

Guinea, G. V., Rojo, F. J., \& Elices, M. (2004). Brittle failure of dry spaghetti, Engineering Failure Analysis, 11(5), 705-714.

Grzybowski, R. A., \& Donnelly, B. J. (1979). Cooking properties of spaghetti: factors affecting cooking quality. Journal of Agricultural and Food Chemistry, 27(2), 380-384.

Lebaud, M. P. (2018). Méthode des trapèzes (p.2-3), Intégration mathématique. Université de Rennes. Retrieved from https://perso.univ-rennes1.fr/marie-pierre.lebaud/agint/ecrit/analyse-reelle/integration-numerique/X-in t-num.pdf

Lucisano, M., Cappa, C., Fongaro, L., \& Mariotti, M. (2012). Characterisation of gluten-free pasta through conventional and innovative methods: Evaluation of the cooking behaviour. Journal of Cereal Science, 56(3), 667-675.

Manthey, F. A., Yalla, S. R., Dick, T. J., \& Badaruddin, M. (2004). Extrusion properties and cooking quality of spaghetti containing buckwheat bran flour. Cereal Chemistry, 81(2), 232-236.

Matsuo, R. R., Bradley, J. W., \& Irvine, G. N. (1972). Effect of protein on the cooking quality of spaghetti. Cereal Chemistry, 49, 707-711.

Moskowitz, H. R., \& Drake, B. (1972). Psychophysical measurement of texture. Journal of Texture Studies, 3, 135-145.

Nazarov, N. (1977). Technology and equipment for the food industry. Food Industry Press, 214.

Novaro, P., D'Egidio, M. G., Mariani, B. M., \& Nardi, S. (1993). Combined effect of protein content and high-temperature drying systems on pasta cooking quality. Cereal Chemistry, 70(6), 716-719.

Pagani, M. A., Lucisano, M., \& Mariotti, M. (2007). Traditional Italian products from wheat and other starchy flours. Handbook of Food Products Manufacturing, Chap. 17.

Palmade, L. (2015). Water in food, Engineering School course notes. University of Montpellier, France.

Raina, C. S., Singh, S., Bawa, A. S., \& Saxena, D. C. (2005). Textural characteristics of pasta made from rice flour supplemented with proteins and hydrocolloids. Journal of Texture Studies, 36(4), 402-420.

Rayas-Duarte, P., Mock, C. M., \& Satterleei, L. D. (1996). Quality of spaghetti containing buckwheat, amaranth, and lupin flours. Cereal Chemistry, 73(3), 381-387.

Schoenlechner, R., Drausinger, J., Ottenschlaeger, V., Jurackova, K., \& Berghofer, E. (2010). Functional properties of gluten-free pasta produced from amaranth, quinoa and buckwheat. Plant Foods Human Nutrition, 65(4), 339-349.

Smewing, J. (1997). Analysing the texture of pasta for quality control. Cereal Food World, 42, 8-13.

Szczesniak, A. S. (1987). Correlating sensory with instrumental texture measurement - An overview of the recent development. Journal of Texture Studies, 18, 1-15.

The engineering toolbox, modulus of elasticity or Young's Modulus - and tensile modulus for common materials. Retrieved from http://www.engineeringtoolbox.com/young-modulus-d_417.html

Vansteelandt, J., \& Delcour, J. A. (1998). Physical behavior of durum wheat starch during industrial pasta processing. Journal of Agricultural and Food Chemistry, 46, 2499-2503.

Verdu, E. F., Galipeau, H. J., \& Jabri, B. (2015). Novel players in Coeliac disease pathogenesis: role of the gut microbiota. Nature Reviews Gastroenterology \& Hepatology, 12, 497-506. 


\section{Copyrights}

Copyright for this article is retained by the author(s), with first publication rights granted to the journal.

This is an open-access article distributed under the terms and conditions of the Creative Commons Attribution license (http://creativecommons.org/licenses/by/4.0/). 